\title{
Muro panel térmico estructural compuesto en guadua y cartón Modelo experimental aplicado al clima de la zona cafetera
}

\section{Renato Cassandro-Cajiao}

Universidad Católica de Colombia, Bogotá (Colombia)

Facultad de Diseño

Maestría en Diseño Sostenible

\section{Cassandro-Caijiao, R. (2018). Muro panel térmico estructu- ral compuesto en guadua $y$ cartón. Modelo experimen- tal aplicado al clima de la zona cafetera. Revista de Arquitectura (Bogotá), 20(2), 90-109. doi: http:/// dx.doi.org/10.14718/ RevArq.2018.20.2.2116}

http://dx.doi.org/10.14718/RevArq.2018.20.2.211

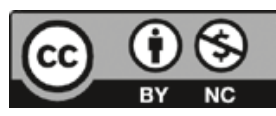

Arquitecto, Universidad Católica de Colombia, Bogotá (Colombia). Magíster en Diseño Sostenible, Universidad Católica de Colombia, Bogotá (Colombia).

Docente del Programa de Arquitectura, Facultad de Diseño, Universidad Católica de Colombia, Bogotá (Colombia).

(D) https://orcid.org/0000-000I-8064-4655

rcassandro@ucatolica.edu.co

\section{Resumen}

Se propone un prototipo de panel compuesto, tipo SIP (Structural Insulated Panel), panel térmico estructural, como muro envolvente de vivienda, elaborado con materiales de origen natural renovables, específicamente guadua y cartón reciclados. El panel se compone de dos tableros externos OSB (Oriented Strand Board), tablero de virutas orientadas, y un aislante intermedio de cartón. En el estudio se elaboran dos modelos SIP experimentales con procesos de fabricación diferentes, los cuales son analizados y comparados con cuatro referentes comercializados a nivel mundial. Todos los paneles son simulados térmica y acústicamente en condiciones climáticas y meteorológicas de la ciudad de Pereira (Risaralda), con el fin de evaluar y comparar los resultados, lo que demuestra la viabilidad y competitividad del panel propuesto. Este estudio espera servir, además, como referencia de futuras investigaciones en la búsqueda de mejores materiales sustentables para la construcción.

Palabras clave: análisis de ciclo de vida, contaminación ambiental, materiales de construcción, panel OSB, panel SIP, recursos forestales, sostenibilidad ambiental.

\section{Structural thermal panel wall composed of bamboo and cardboard. Experimental model applied to the climate of the Coffee Region}

\section{Abstract}

This paper proposes a SIP (Structural Insulated Panel) type composite panel prototype, a structural thermal panel, as a building envelope wall made of renewable natural materials, specifically bamboo and recycled cardboard. The panel consists of two external OSB (Oriented Strand Board) boards, oriented chipboard, and an intermediate cardboard insulation. In the study, two experimental SIP models are developed, using different manufacturing processes, which are analyzed and compared with four commercial references worldwide. All the panels are simulated thermally and acoustically in the climatic and meteorological conditions of the city of Pereira (Risaralda), in order to evaluate and compare the results, demonstrating thus the viability and competitiveness of the proposed prototype. In addition, this study aims to serve as a reference point for future research in the search for better sustainable construction materials.

Keywords: Life-cycle analysis, environmental contamination, construction materials, OSB panel, SIP panel, forest resources, environmental sustainability.

\section{Muro painel térmico estrutural composto de bambu e papelão.} Modelo experimental aplicado ao clima da zona cafeeira

\section{Resumo}

Propõe-se um protótipo de painel composto, tipo SIP (Structural Insulated Panel), painel térmico estrutural, como muro envolvente de moradia elaborado com materiais de origem natural renováveis, em específico bambu e papelão reciclado. $O$ painel está composto de duas placas externas OSB (Oriented Strand Board), placas de aparas orientadas e um isolante intermediário de papelão. Neste estudo, foram elaborados dois modelos SIP experimentais com processos de fabricação diferentes, os quais são analisados e comparados com quatro referentes comercializados no mundo inteiro. Todos os painéis são simulados térmica e acusticamente em condições climáticas e meteorológicas da cidade de Pereira (Colômbia), a fim de avaliar e comparar os resultados, o que demonstra a viabilidade e competitividade do proposto. Este estudo espera servir, além disso, como referência para futuras pesquisas na busca de melhores materiais sustentáveis para a construção.

Palavras-chave: análise de ciclo de vida, poluição ambiental, materiais de construção, painel OSB, painel SIP, recursos florestais, sustentabilidade ambiental. 


\section{Introducción}

\section{El contexto}

Este artículo presenta los resultados de la investigación "Muro panel compuesto en guadua para vivienda" realizada como trabajo de grado para optar por el título de magíster en Diseño Sostenible de la Universidad Católica de Colombia, adscrito a la línea de Diseño y Tecnología. El proyecto se realizó entre los años 2015 a 2017, y su objetivo principal fue desarrollar un modelo de muro panel compuesto elaborado a partir de materiales de origen natural renovable, como elemento envolvente o muro exterior para la vivienda en zona tropical cálida.

El continuo crecimiento de la población mundial y su demanda de vivienda hace que su construcción sea un tema de investigación constante en la búsqueda de optimizar los materiales referidos a la resistencia, durabilidad, funcionalidad, economía, bajo impacto ambiental y consumo energético en su ciclo de vida.

Reemplazar los materiales convencionales de la construcción de vivienda por materiales naturales renovables como la guadua, en lugares donde existen cultivos y producción, es una alternativa tangible de sostenibilidad social y económica, ya que su industrialización tendrá beneficios, como la generación de empleo, y bajos costes de construcción habitacional con confort interior.

La importancia de este árbol o gramínea en la construcción y la industria en Colombia es evidente y con futuro promisorio. Según afirman el ingeniero Edgar Giraldo (2003, p. 19) y Mejía, et al. (2009), "en Colombia aproximadamente 100.000 personas derivan su sustento del aprovechamiento, manejo y comercialización de la Guadua". Sus beneficios van desde su plantación como la mejor captadora de contaminantes de $\mathrm{CO}^{2}$, hasta su generación de oxígeno, rápido crecimiento y multiplicidad de aplicaciones (construcción, textilería, ornamentación y medicina).

Las Corporaciones Autónomas Regionales (CAR) son las entidades encargadas de velar por el cuidado y aprovechamiento de los recursos naturales, por medio del Decreto Único Reglamentario del Sector Ambiente y Desarrollo Sostenible (Decreto 1076 de 2015), y el Estatuto Forestal de la región el cual reglamenta los aprovechamientos de esta y de otras especies. En este caso, la entidad reglamenta el manejo sostenible de la guadua desde sus plantaciones hasta la ejecución de proyectos que permitan su desarrollo con beneficio económico y social para la región donde existe la mayor cantidad de plantacio- nes, es decir, el eje cafetero, que comprende los departamentos de Caldas, Quindío y Risaralda, Tolima y Valle del Cauca (Mejía y Moreno, 2013).

De acuerdo con una visita de campo realizada a mediados de junio del año 2017 a las fábricas o industrias de Induguadua en la Tebaida, y Armeideas en Guadua en Calarcá, localizadas en la zona cafetera, se pudo evidenciar que el porcentaje de residuos resultantes oscilaban entre un 30 a $40 \%$, constatando que en la mayoría de los casos estos son utilizados como combustible para el proceso de secado de la misma guadua o la elaboración de carbón, lo que produce gran cantidad de $\mathrm{CO}^{2}$ y contamina aún más el ambiente. Por tal razón, es prioritario proponer alternativas de utilización de los residuos que no contaminen y se aprovechen sus grandes cualidades físicas, mecánicas y estéticas para una diversidad de usos.

La situación mundial por el cambio climático, la contaminación ambiental y el aumento de la población obliga a la búsqueda permanente de alternativas y soluciones más eficientes de sostenibilidad, vistas desde su proceso de producción, fabricación, utilización y reciclaje, hasta la reducción de consumo energético, con la mínima producción de emisiones de $\mathrm{CO}^{2}$ y otros gases contaminantes.

El impacto ambiental y consumo energético de los materiales convencionales para la construcción, como cemento, concreto, arcilla y PVC, representa una de las grandes preocupaciones mundiales, lo que hace necesario repensar la arquitectura de la edificación volviendo a sus orígenes en el sector de la construcción, utilizando materiales locales con bajos costos energéticos y un mínimo impacto ambiental.

En la historia de Colombia, en los asentamientos informales de la población en torno a las ciudades principales, la guadua ha tenido -y sigue teniendouna presencia constante y representativa, siendo uno de los motivos que dio paso al despectivo término de madera de pobres (Colorado, s.f).

\begin{abstract}
La idea generalizada que la guadua no ofrece seguridad para construcciones complejas y que su uso debía limitarse únicamente a viviendas de tipo popular caló de tal forma en los arquitectos e ingenieros, que durante años desconocieron testimonios históricos que hablaban de una tradición que se desarrolló desde finales del siglo XIX, en la que fue precisamente el bambú el material preferido para construir y contrarrestar los sismos que sacudían la región cafetera y otras zonas de similares condiciones en el país (párr. 32).
\end{abstract}

Hoy por hoy se puede afirmar que estos antecedentes despertaron en profesionales, técnicos, investigadores y cultivadores una visión futurista 


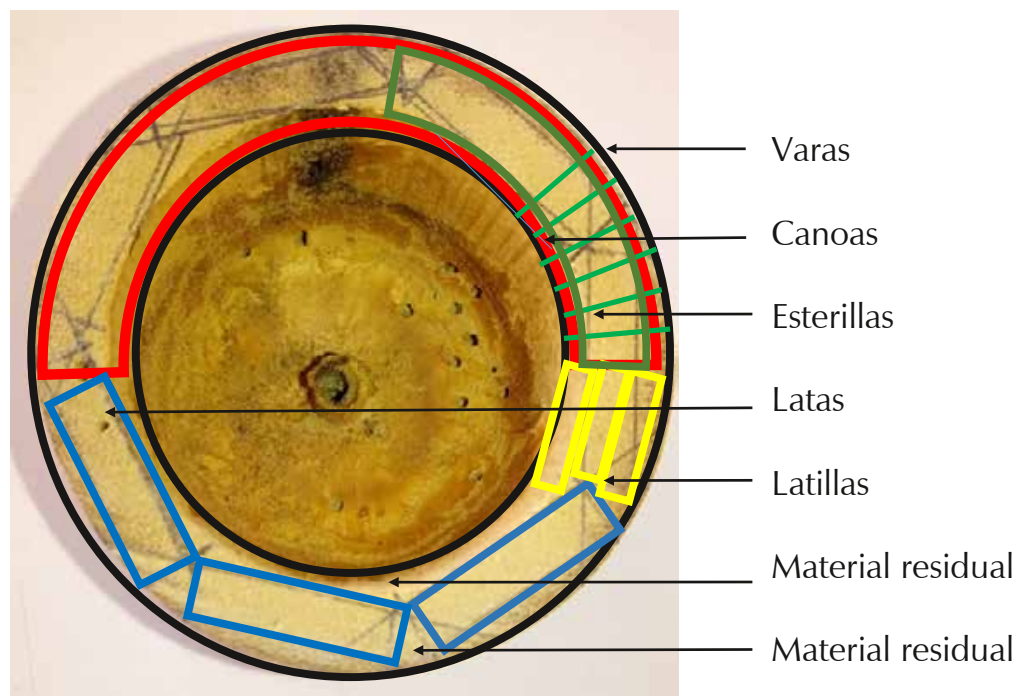

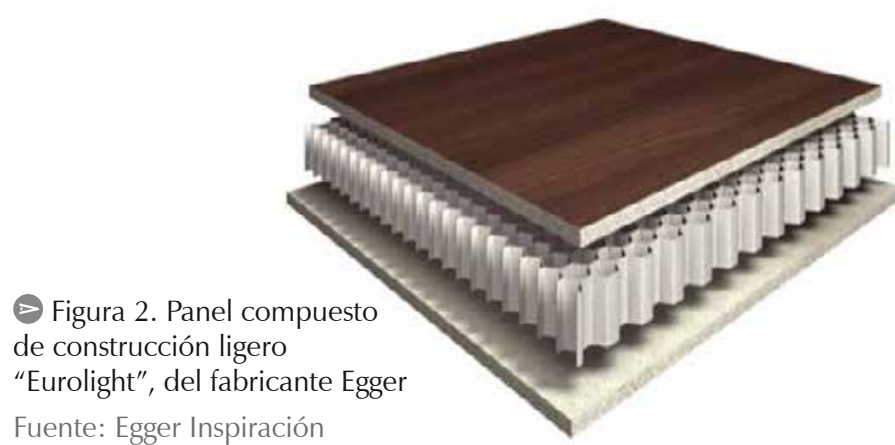

Eurolight
(A) Figura 1. Elementos extraídos para la construcción

Fuente: elaboración propia, 2017, CC BY. de proyección hacia el aprovechamiento de este recurso natural, renovable y sostenible, que hace urgente su materialización en proyectos puntuales.

La investigación se enfocó en el aprovechamiento de la guadua, la cual crece en condiciones climáticas específicas de zona tropical, de temperatura cálida templada, que configuran una parte representativa del territorio colombiano. Es utilizada en la construcción por sus óptimas propiedades físicas y técnicas, tanto que desde la época prehispánica (con la especie nativa "guadua angustifolia") fue protagonista en la construcción de la vivienda de pequeñas poblaciones y zonas periféricas de las ciudades (Varela y Chaviano, 2013). La guadua, en su proceso de transformación para la fabricación de varas, canoas, latas, latillas o fibras, produce un gran porcentaje de residuos, que generalmente son utilizados como combustible o transformados en carbón vegetal, lo que genera mayor contaminación ambiental.

La envolvente de una edificación tiene como función principal mantener un aislamiento térmico constante y comprende todos los elementos que dividen o separan el exterior del interior; su propósito fundamental es mantener el clima de confort interno promedio entre 18 y $20^{\circ} \mathrm{C}$.

El objetivo específico de investigación fue aprovechar este material residual resultante, que significa aproximadamente el $40 \%$ del total de la guadua (Figura 1), y transformarlo en virutas $u$ hojuelas para la fabricación de los tableros OSB (Oriented Strand Board), de acuerdo con la normativa internacional (Garay y Damiani, 2013), a fin de constituir las superficies externas principales de un panel SIP (Structural Insulated Panel) o panel térmico estructural (Cárdenas, et al., 2015) (Figura 2), conformado por un aislante intermedio en cartón reciclado para que pueda ser utilizado como envolvente de la vivienda en la región cafetera, y con esto reemplazar materiales convencionales $y$, a su vez, ofrecer una alternativa sostenible.

\section{El panel compuesto SIP}

La industrialización de productos a base de madera residuo o deshecho ha resuelto muchos problemas de déficit de materia prima a nivel mundial, y ha abierto la oportunidad de incrementar sus aplicaciones, exaltando cualidades como el alto coeficiente de resistencia y las propiedades térmicas, lo que se refleja en el crecimiento de su producción de 12 millones de $\mathrm{m}^{3}$ en 1950, a 125 millones de $\mathrm{m}^{3}$ en la actualidad (Fernández, 1993). Uno de estos productos son los tableros OSB, conocidos como tableros de virutas cruzadas.

Estos tableros son un producto relativamente nuevo, la Organización de las Naciones Unidas para la Agricultura y la Alimentación (FAO), en su base de datos estadísticos posee cifras mundiales sobre los OSB, que muestran un crecimiento del $7 \%$ en la producción y comercialización en el año 2015 con respecto al año anterior, debido a la cada vez mayor tendencia a la producción ecosostenible (FAO, 2016). Pese a esto, en Colombia no hay producción de tableros OSB, y la demanda es muy baja, probablemente debido a la falta de conocimiento como alternativa constructiva y a los procesos de industrialización. La experiencia en otros países demuestra que estos tableros son una alternativa real, sostenible y eficiente para la construcciónn liviana, rápida y resistente.

Actualmente, los materiales de un tipo de panel compuesto SIP (panel de aislamiento estructural o paneles estructurales térmicos), estan constituidos por dos tableros externos fabricados con hojuelas o virutas de pino o abeto (OSB), prensadas y unidas mediante adhesivos químicos y orientadas en el sentido longitudinal, y por dos internas, cruzadas en el sentido perpendicular (Figura 3). Adicionalmente, se componen de un núcleo interno como aislante térmico, generalmente en poliestireno (Arquigráfico, 2016).

El tablero OSB se comercializa generalmente en formato de $244 \times 122 \mathrm{~cm}(8 \times 4 \mathrm{ft})$ y espesor entre 7 y $18 \mathrm{~mm}$, sus usos principales en la construcción son como bases de cubiertas, vigas, viguetas, pisos, escaleras, paneles para muros exteriores e interiores, entre otros.

Los OSB, de acuerdo con sus características y especificaciones, se clasifican en cuatro grupos, reconocidos por sus fabricantes a nivel mundial; 


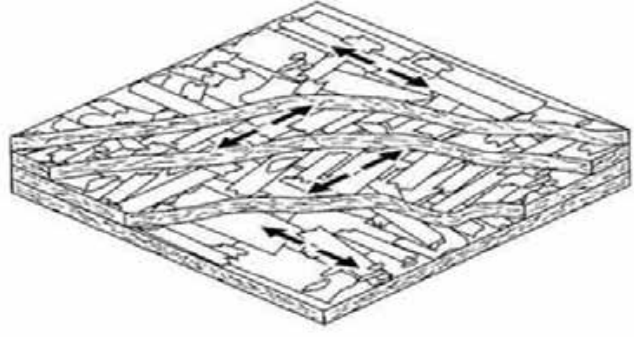

(A) Figura 3. Orientación cruzada de virutas en el tablero OSB

Fuente: Arquigráfico (2016).

el OSB-3, desde el punto de vista del consumo, se ha estandarizado para el uso específico de panel como muro envolvente, y es el usado para esta investigación. A continuación se describen los usos de los cuatro grupos:

OSB-1. Uso interior, básicamente mobiliario. Se trata de la gama más básica y su comercialización actualmente es muy reducida.

OSB-2. Aplicaciones de carga en ambientes secos.

OSB-3. Aplicaciones de carga en ambientes relativamente húmedos, es el tipo de tablero más utilizado y el que mejor relación calidad-precio tiene.

OSB-4. Altas prestaciones de carga en ambientes relativamente húmedos (Santana, 2015).

El aislante interno más utilizado en los paneles SIP es la lámina EPS (poliestireno expandido) que está constituido por $98 \%$ aire y $2 \%$ poliestireno. La capacidad de aislamiento térmico de un material está definida por su conductividad termica, su unidad es $\mathrm{W} /(\mathrm{m} \cdot \mathrm{K})$ y depende de la densidad $\left(\mathrm{kg} / \mathrm{m}^{3}\right)$ del material. Por tanto, la conductividad térmica es mayor en láminas con bajas densidades, disminuye a medida que aumenta la densidad y alcanza un mínimo por encima de los 30 $\mathrm{kg} / \mathrm{m}^{3}$ (Grupo Isotex, 2015).

El poliestireno expandido no tiene límite de temperatura baja, la temperatura máxima permisible depende del tiempo de exposición (Figura 4). En el caso de exposición corta puede soportar temperaturas mayores a $100^{\circ} \mathrm{C}$. Sin embargo, por un periodo largo tiende a deformarse y perder su rigidez.

\section{Metodología}

La investigación fue realizada teniendo en cuenta, en primera instancia, los antecedentes y productos similares que existen hoy en el mercado, utilizando un método experimental-descriptivo y considerando características específicas del panel aplicadas a un lugar y clima determinados, los cuales son simulados de manera virtual por medio de software térmico y acústico, que indican su desempeño; adicionalmente, se realizaron pruebas de laboratorio complementarias a

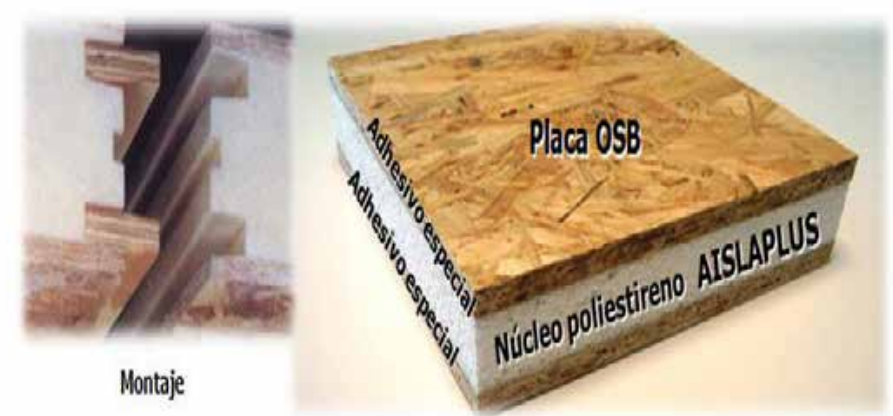

(A) Figura 4. Sistema SIP, componentes Fuente: Klasspanel (s. f.).

Inicio de la investigación

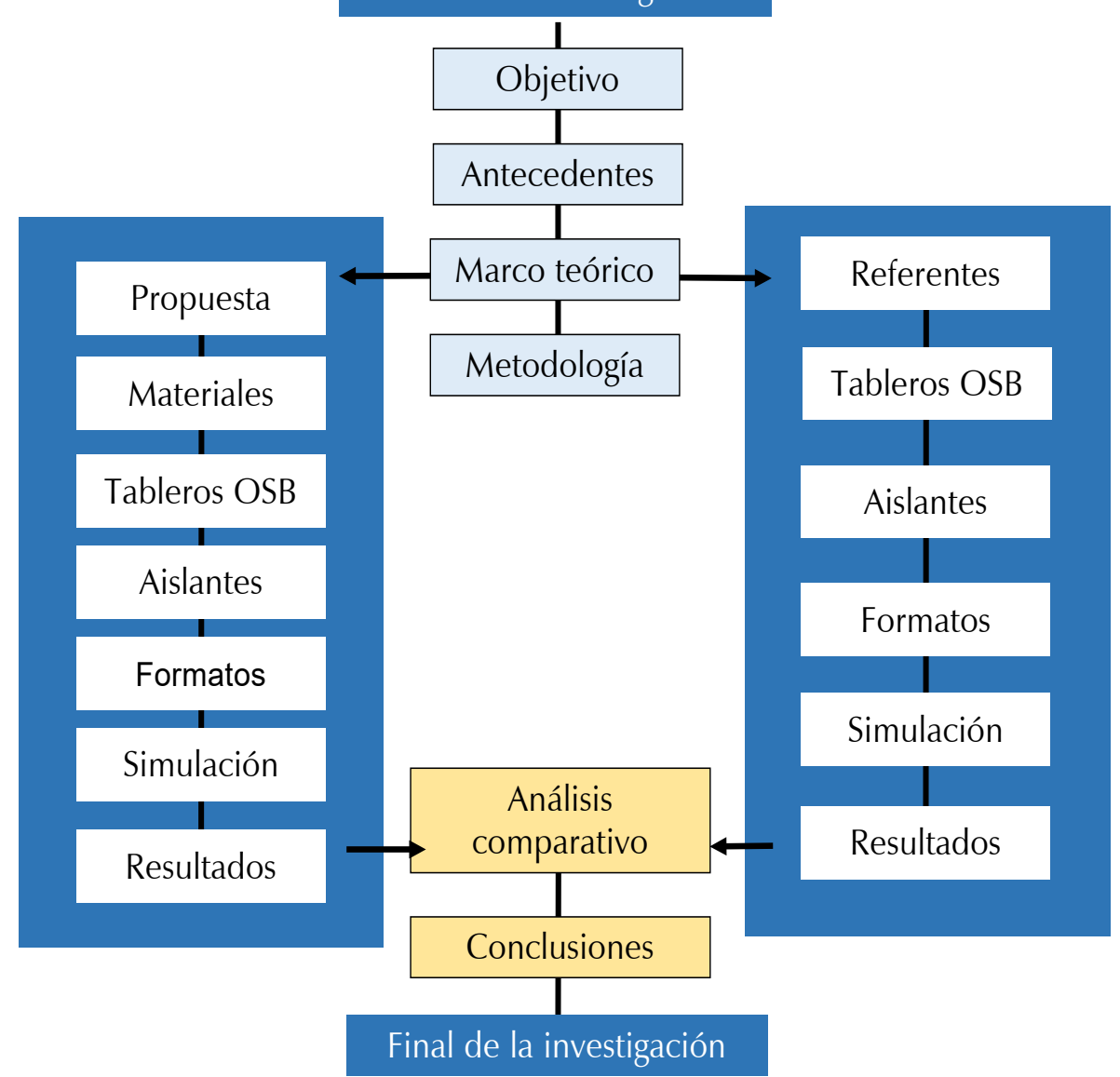

los modelos propuestos, con resistencia al esfuerzo horizontal y vertical, y absorción acústica.

Es importante aclarar que el alcance de la investigación se limita a la realización de modelos probeta que permiten evaluar el comportamiento térmico, acústico, peso y resistencia horizontal y vertical, para ser comparados con los valores indicados en las fichas técnicas que describe cada fabricante, de acuerdo con la normatividad de su país de origen (Apa's Corporate, 2015). Esto, sin tener en cuenta la totalidad de las características del producto final, lo cual requeriría mayor cantidad de tiempo y recursos económicos.

De acuerdo con la Figura 5, correspondiente al mapa conceptual del desarrollo de la investigación, se llevaron procesos paralelos entre los referentes y las propuestas, de tal modo que direccionaran los ajustes o inconvenientes de la propuesta.
A Figura 5. Mapa conceptual del desarrollo de la investigación

Fuente: elaboración propia, 2017, CC BY. 


\section{Procedimiento experimental}

1. Selección de cuatro referentes que se muestran en la Tabla 1. Estos fueron definidos de acuerdo con varios aspectos: la similitud entre ellos, en cuanto a sus dimensiones referidas al espesor total de aproximadamente $100 \mathrm{~mm}$, a los materiales de los tableros (madera aglomerada) y al uso específico del panel como pared exterior o envolvente de la edificación (objetivo del modelo propuesto); adicional a esto, que estuvieran dentro de la mayor representación comercial a nivel internacional.

2. Realización de las simulaciones térmica y acústica de cada referente (Tabla 2), por medio de los software Therm 7.5 y DBK AISLA 3.01, tomando como datos climáticos los de la ciudad de Pereira (Risaralda), la cual fue seleccionada por ser una de las mayores cultivadoras y consumidoras de guadua para sus construcciones en la zona cafetera de Colombia, con avances tecnológicos, sociales y ambientales de la región. Y en cuanto a las características térmicas del producto, se tomaron los datos de las fichas técnicas, que a su vez corresponden a tablas homologadas y estandarizadas a nivel internacional, referentes a las propiedades térmicas de los materiales de construcción (Arquimaster, s.f.).

3. Elaboración de dos modelos experimentales con el apoyo de las empresas Muiskay SAS en Bogotá y Primadera SAS en Gachancipá (Cundinamarca) para la elaboración de los tableros OSB con viruta de guadua, siguiendo las características generalizadas de los referentes en cuanto a dimensiones y espesores, y utilizando los materiales básicos propuestos de viruta de guadua y cartón reciclado.

4. Simulaciones térmicas y acústica por medio de los software Therm 7.5 y DBK AISLA 3.01, para los modelos experimentales, con los datos climáticos de Pereira (Risaralda).

5. Ensayos de laboratorio de resistencia a la compresión y acústica de los dos modelos propuestos.

6. Elaboración de cuadros comparativos, con los resultados obtenidos en las simulaciones tanto de los referentes como de los modelos experimentales.

7. Resultados y discusión. Análisis comparativo del comportamiento térmico y acústico.

8. Conclusiones.

\section{Resultados}

\section{Referentes}

Se parte del marco teórico construido desde la documentación y fuentes bibliográficas sobre los paneles SIP (compuestos de tableros OSB y aislante intermedio), así como de sus antecedentes históricos, materiales, características técnicas y clasificación de acuerdo con las especificaciones que rigen a nivel internacional.

Se seleccionan los cuatro referentes más representativos en el mercado internacional (Tabla 1) teniendo en cuenta solo las características (espe- sores, dimensiones, materiales, peso, resistencia y transmisión térmica) y usos similares al propuesto en la investigación. Los datos de cada panel SIP, necesarios para la simulación, fueron obtenidos de las especificaciones y fichas técnicas de cada fabricante, donde generalmente se informa el valor $U$ (transmisión térmica) y $R=1 / U$ (resistencia térmica), mediante tablas de conocimiento y aplicación a nivel mundial (Arquimaster, s.f.; Vagge y Czajkowski, 2012), también indicando su espesor total y la composición.

La tramitancia térmica total del panel SIP es el resultado de la sumatoria de los valores de sus componentes, de acuerdo con: tablero exterior OSB + aislante + tablero interior OSB.

Se recopilan los datos térmicos principales de cada panel SIP, necesarios para la simulación, los cuales fueron obtenidos de las especificaciones y fichas técnicas de cada fabricante, donde la característica generalizada es la utilización de un aislante en poliestireno y dos tableros OSB, fabricados con virutas de pino y abeto.

Para el análisis y las simulaciones se tuvieron en cuenta las temperaturas máximas y mínimas con promedio anuales, además de precipitación y humedad relativa, datos extraídos del Ideam y de Meteonorm de la ciudad de Pereira. Cabe resaltar que se busca una única condición físico-espacial de muro, con relación exterior e interior (adentro-afuera), sin tener en cuenta espacio o ambiente alguno, ya que contaría con variables de toda índole como: tipo de terreno, cubierta, nivel de fenestración, etc., y el propósito aquí presentado es considerar el aporte individual que tendría el panel específicamente.

La humedad relativa promedio anual del 76,5\% y promedio lluvias 228 días/año, son factores que inciden directamente en los valores de la resistencia del panel a la humedad (Weather Atlas, 2016). Para ello los paneles de los referentes están categorizados como los tableros OSB/3 (según la Norma Europea UNE - en 300), diseñados para funcionar en lugares húmedos y que básicamente se refieren al producto adhesivo con acción impermeabilizante, con el cual se fabrican los tableros de fachada o envolventes. Se tuvieron en cuenta además los datos de resistencia, espesor y peso por metro cuadrado de los paneles referentes, de manera tal que se puedan comparar con los modelos experimentales.

\section{Simulación térmica de los referentes}

Los resultados obtenidos en los cuatro referentes, sin considerar puentes térmicos ya que el panel pretende ser adaptado a estructuras existentes o particulares de diferente característica, presentan variables mínimas debido a su constitución similar. Su diferencia de temperatura interior de acuerdo con la condición externa nos indica valores de confort con diferencias promedio de 2,1 a $2,8{ }^{\circ} \mathrm{C}$ en las temperatura bajas o mínimas, y una disminución promedio de 3,2 a 4,0 ${ }^{\circ} \mathrm{C}$ en las temperaturas altas o máximas (Tabla 2). 


\section{Características referentes paneles SIP}

\section{DESCRIPCIÓN}

1.1 Fabricante

1.2 País

1.3 Referencia producto

1.4 Imagen
PANEL 1

THERMOCHIP. By Cupa Group.

España

$\mathrm{OSB}(\mathrm{TOH})$

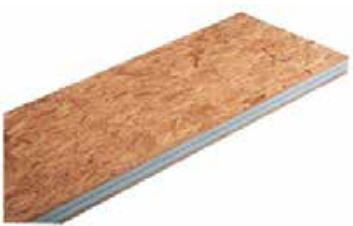

PANEL 2

HEMSEC SIPS. Structural Insulated Panel Inglaterra

PANEL THICKNESS - RESIDENTIAL

\section{COMPOSICIÓN}

1.5 Página web

www.thermochip.com/empresa/sobre-nosotros/

www.hemsecsips.com/products-SIP_Residential.html

2.1 Formato en milímetros

$2440 \times 600$

$2440 \times 1200$

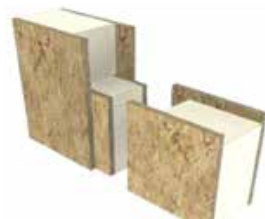

2.2 Composicion panel tricapa

Osb + Poliestireno + Aglomerado hidrofugo

2.2.1 Tablero interno

Osb $15 \mathrm{~mm}$

2.2.2 Aislante intermedio

Poliestireno extruido $80 \mathrm{~mm}$ y densidad de $30 \mathrm{~kg} / \mathrm{m}^{3}$

2.2.3 Aislante externo

Aglomerado hidrofugo $16 \mathrm{~mm}$

2.4 Espesor total en milímetros

$111 \mathrm{~mm}$

Osb + Espuma rígida + Osb

Osb $11 \mathrm{~mm}$

Espuma rigida poliuretano103 mm, no indica densidad

Osb $11 \mathrm{~mm}$

$125 \mathrm{~mm}$

\section{ESPECIFICACIONES}

3.1 Peso total panel $\times \mathrm{m}^{2}$

$19,17 \mathrm{~kg} / \mathrm{m}^{2}$

$18,57 \mathrm{~kg} / \mathrm{m}^{2}$

3.2 Carga vertical máxima

$1435 \mathrm{~kg} / \mathrm{m}^{2}$

No indica

$345 \mathrm{~kg} / \mathrm{m}^{2}$

No indica

$0,360 \mathrm{~W} / \mathrm{M}^{2} \mathrm{k}$

\section{Características referentes paneles SIP}

\section{DESCRIPCIÓN}

1.1 Fabricante

1.2 País

1.3 Referencia producto

1.4 Imagen

1.5 Página web
PANEL 3

THE WALL. Structural Insulated Panel

Estados Unidos

PANEL OSB-OSB

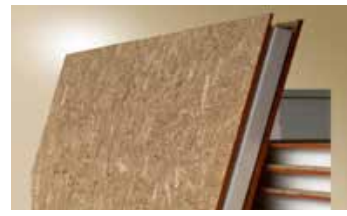

http://www.thewall.cl/index.php?route= product
PANEL 4

LP. Building Product

Chile

PANEL SIP TÉRMICO ESTRUCTURAL

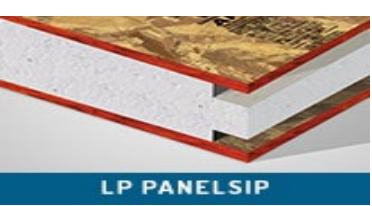

https://pchile.cl/es-ES/producto/otros/lp-panelsip

\section{COMPOSICIÓN}

2.1 Formato en milímetros

2.2 Composicion panel tricapa

2.2.1 Tablero interno

2.2.2 Aislante intermedio

2.2.3 Aislante externo

2.4 Espesor total en milímetros

\section{ESPECIFICACIONES}

3.1 Peso total panel $\times \mathrm{m}^{2}$

3.2 Carga vertical máxima

3.3 Carga horizontal tal máxima

3.4 Transmisión térmica. U total
$1220 \times 2440$

Osb + Poliestireno + Osb

Osb $11,1 \mathrm{~mm}$

Poliestireno expandido $92 \mathrm{~mm}$ y densidad de $15 \mathrm{~kg} / \mathrm{m}^{3}$

Osb 11,1 mm

$114 \mathrm{~mm}$
$1220 \times 2440$

Osb + Poliestireno + Osb

$$
\text { Osb } 9,5 \mathrm{~mm}
$$

Poliestireno expandido $76 \mathrm{~mm}$ y densidad de $15 \mathrm{~kg} / \mathrm{m}^{3}$

Osb $9,5 \mathrm{~mm}$

$95 \mathrm{~mm}$

A Tabla 1. Características referentes paneles SIP

Fuente: elaboración propia, 2017.

Vol. 


\begin{tabular}{|cccc}
\hline PANEL 1 & PANEL 2 & PANEL 3 & PANEL 4 \\
\hline THERMOCHIP. By Cupa Group. & HEMSEC SIPS. Structural Insulated Panel & THE WALL. Structural Insulated Panel & LP. Building Product. \\
\hline OSB (TOH) & PANEL THICKNESS - RESIDENTIAL & PANEL OSB-OSB & PANEL SIP TERMICO ESTRUCTURAL \\
\hline
\end{tabular}

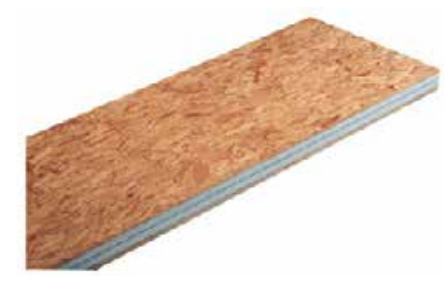

$0,360 \mathrm{~W} / \mathrm{m}^{2} \mathrm{k}$

(1)Osb + (2) Poliestireno $+(3)$ Aglomerado hidrofugo

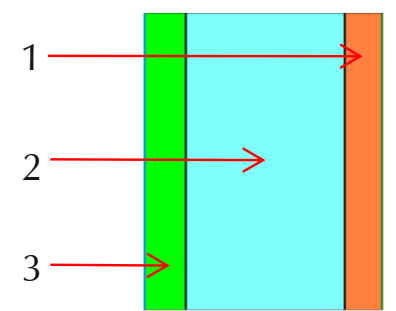

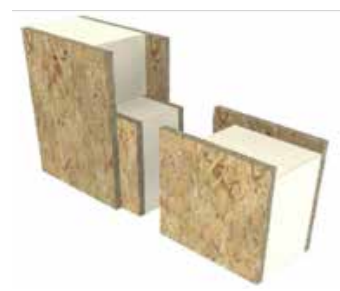

$0,260 \mathrm{~W} / \mathrm{m}^{2} \mathrm{~K}$

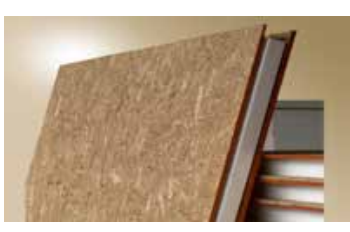

$0,364 \mathrm{~W} / \mathrm{m}^{2} \mathrm{~K}$

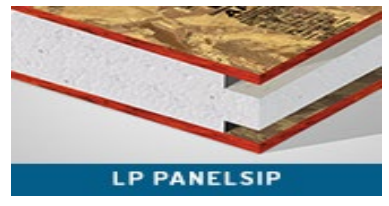

$0,515 \mathrm{~W} / \mathrm{m}^{2} \mathrm{~K}$

$(1) \mathrm{Osb}+(2)$ Espuma rígida $+(3) \mathrm{Osb}$

$(1)$ Osb + (2) Poliestireno $+(3)$ Osb

(1)Osb + (2) Poliestireno + (3)Osb

1

2

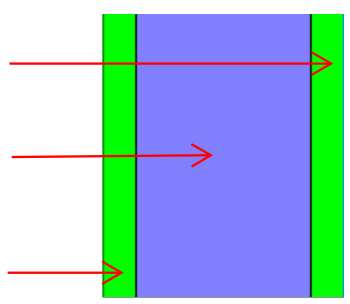

1

2

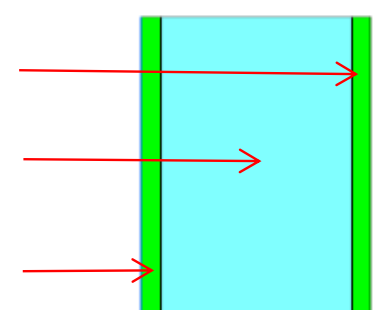

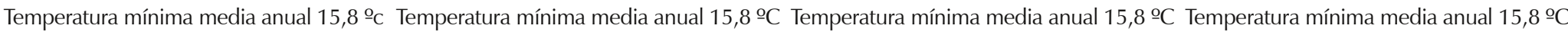
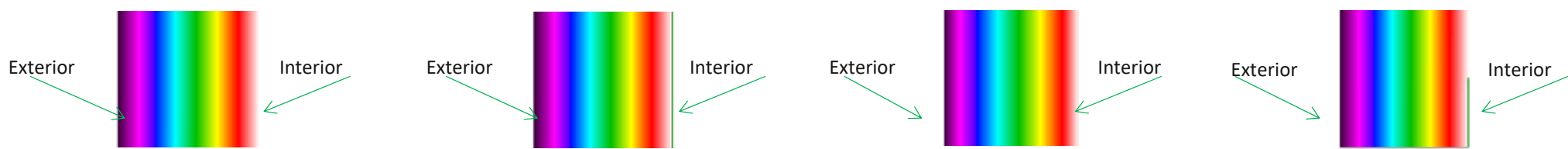

Temperatura máxima media anual 26,3ㄷ C Temperatura máxima media anual 26,3ํㅡ Temperatura máxima media anual 26,3ำ Temperatura máxima media anual 26,3ำ

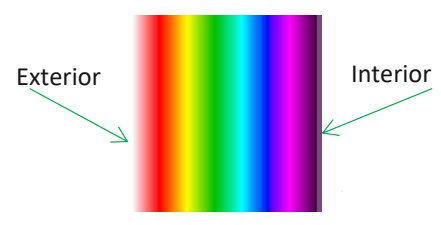

Variable en bajas temperaturas se eleva al interior promedio $1,32^{\circ} \mathrm{C}$

Variable de altas temperaturas se baja promedio $2,59 \stackrel{\circ}{\mathrm{C}}$

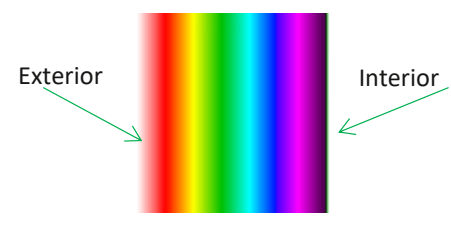

Variable en bajas temperaturas se eleva al interior promedio $1,7 \circ \mathrm{C}$

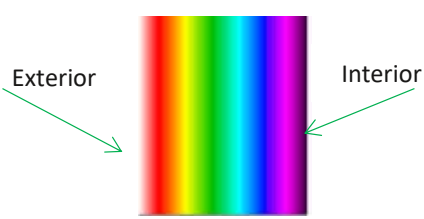

Variable en bajas temperaturas se eleva al interior promedio $1,75^{\circ} \mathrm{C}$

Variable de altas temperaturas se baja promedio $2,63{ }^{\circ} \mathrm{C}$

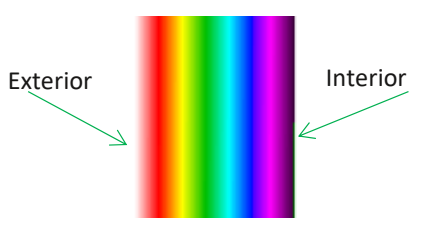

Variable en bajas temperaturas se eleva al interior promedio $1,58^{\circ} \mathrm{C}$

Variable de altas temperaturas se baja promedio $2,37^{\circ} \mathrm{C}$ (a) Tabla 2. Resultados de transferencia de calor por conducción bidimensional de acuerdo con los componentes de los paneles

Fuente: elaboración propia, 2017.

\section{Simulación acústica - Referentes}

Los ruidos generalmente están compuestos por variaciones de presión de diferentes frecuencias. El sistema auditivo humano está capacitado para oír sonidos de frecuencias comprendidas entre los 20 y los $20.000 \mathrm{~Hz}$. El aislamiento, en todos los casos, se muestra como una constante ascendente que presenta menor absorción de ruido cuando aumenta la frecuencia (Tabla 3). Sus variaciones son mínimas ya que el nivel de absorción va directamente a la densidad de los materiales y sus espesores, que para este caso son muy similares, y se presentan como rango de referencia para este producto.

\section{Desarrollo de la experimentación \\ Modelo 1}

Materiales

a) Hojuelas de fibra de guadua (Figura 6) elaboradas con el residuo producto de la fabricación de las tablillas, canoas, esterillas y otros cortes que se comercializan para artesanías y construcción. En este caso obtenido por intermedio de la empresa Induguadua S.A, ubicada en el Kilómetro 15 vía Armenia-La Tebaida. 


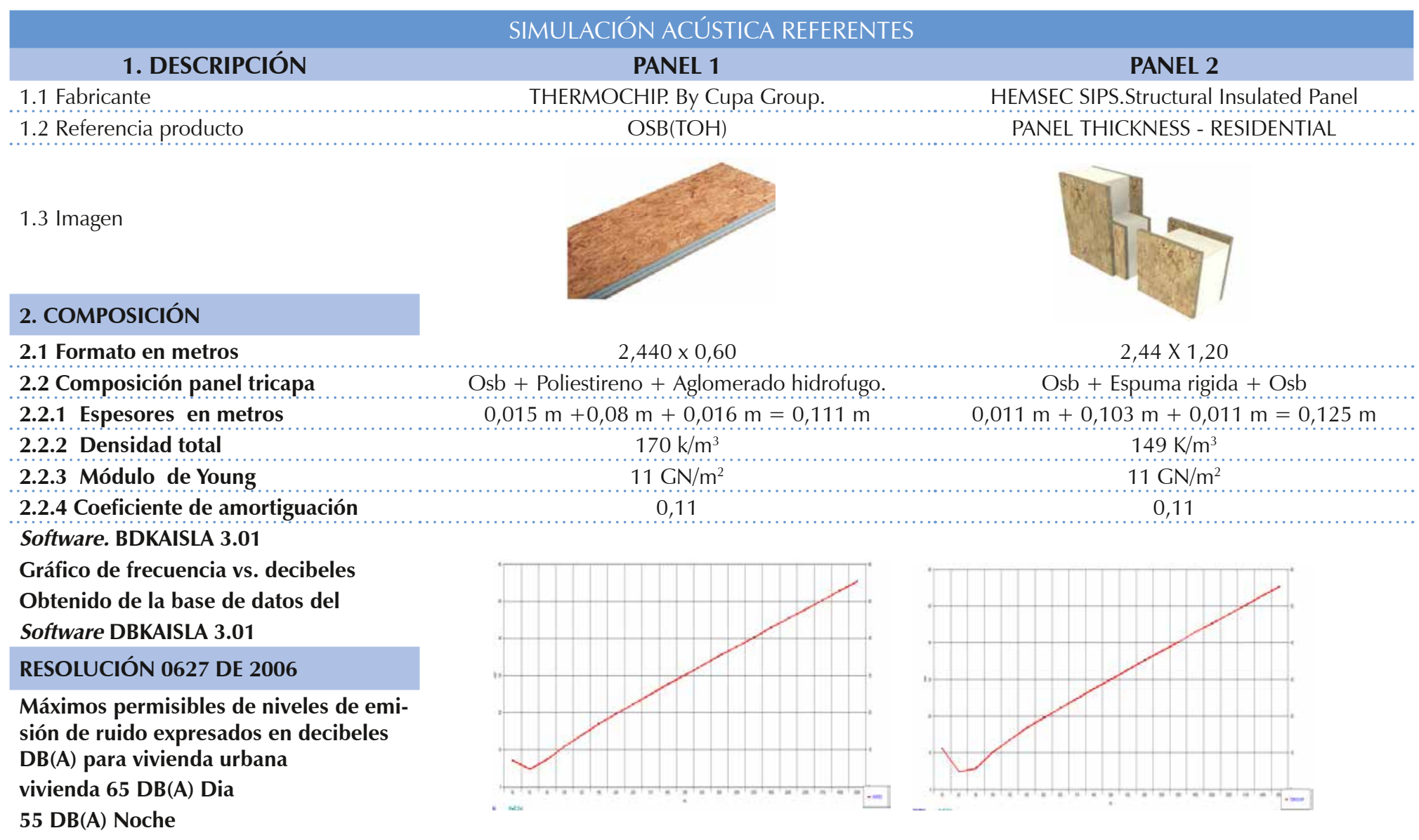

$\begin{array}{ccc} & \text { SIMULACIÓN ACÚSTICA REFERENTES } & \text { PANEL } 4\end{array}$

1.1 Fabricante
1.2 Referencia producto

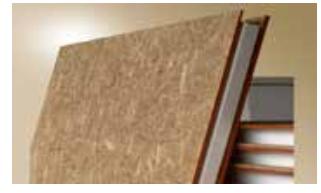

$2,44 \times 1,20$

Osb + Poliestireno + Osb

$0,0111 m+0,092 m+0,0111 m=$
$140 \mathrm{~K} / \mathrm{m}^{3}$
$11 \mathrm{GN} / \mathrm{m}^{2}$
0,11

LP. Building Product. PANEL SIP TERMICO ESTRUCTURAL

\subsection{Formato en metros}

2.2.1 Espesores en metros

2.2.2 Densidad total

2.2.3 Módulo de Young

2.2.4 Coeficiente de amortiguación

SOFWARE. BDKAISLA 3.01

Gráfico de frecuencia vs. decibeles

Obtenido de la base de datos del

Software DBKAISLA 3.01

\section{RESOLUCIÓN 0627 DE 2006}

Máximos permisibles de niveles de emisión de ruido expresados en decibeles $\mathrm{DB}(\mathrm{A})$ para vivienda urbana $=$ vivienda 65 DB(A) Día 55 DB(A) Noche

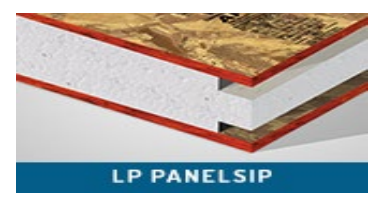

$2,44 \times 1,20$

Osb + Poliestireno + Osb $0,0095 m+0,067 m+0,0095 m$ $176 \mathrm{k} / \mathrm{m}^{3}$

$11 \mathrm{GN} / \mathrm{m}^{2}$ 0,11 b) Adhesivo para la formación de los tableros. Pegatex, Carpincol 2500: pegante sinético de PVA (poliacetato de vinilo) de alta concentración a base de agua.

c) Tubos de cartón reciclados de papel higiénico. Estos fueron recolectados por aproximadamente dos meses, en hogares de personas conocidas (Figura 6).

d) Adhesivo PVA - 60 de pegante para la unión de las tres capas.

e) Barniz impermeabilizante para exterior de permanente contacto con la humedad.
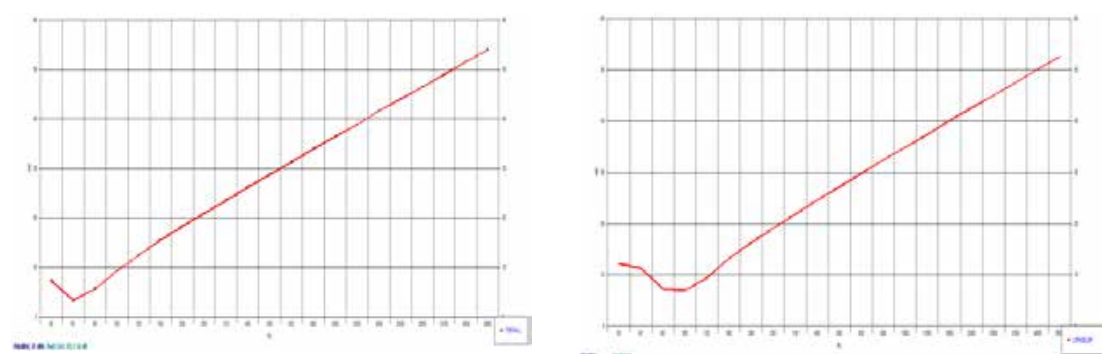

(4) Tabla 3. Simulación acústica de los referentes. Software DBKAISLA Fuente: elaboración propia, 2017.

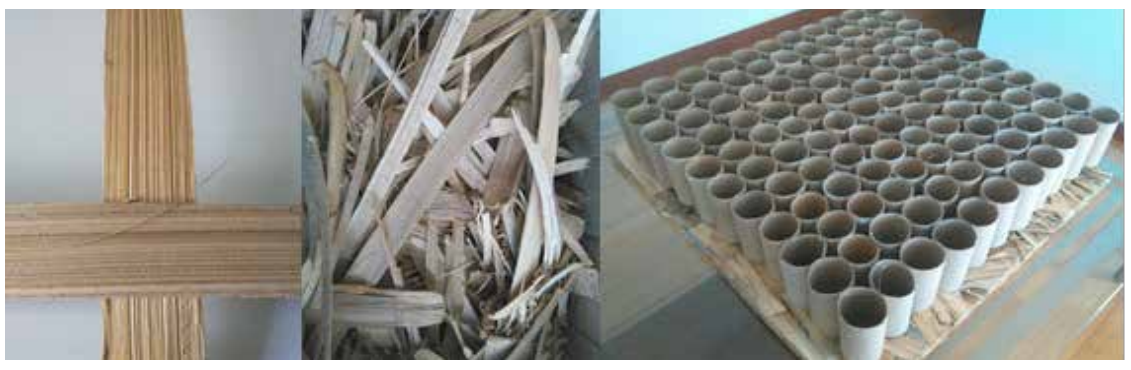

(A) Figura 6. Fibra de guadua reciclada y tubos de cartón reciclados Fuente: elaboración propia, 2017, CC BY-ND. 


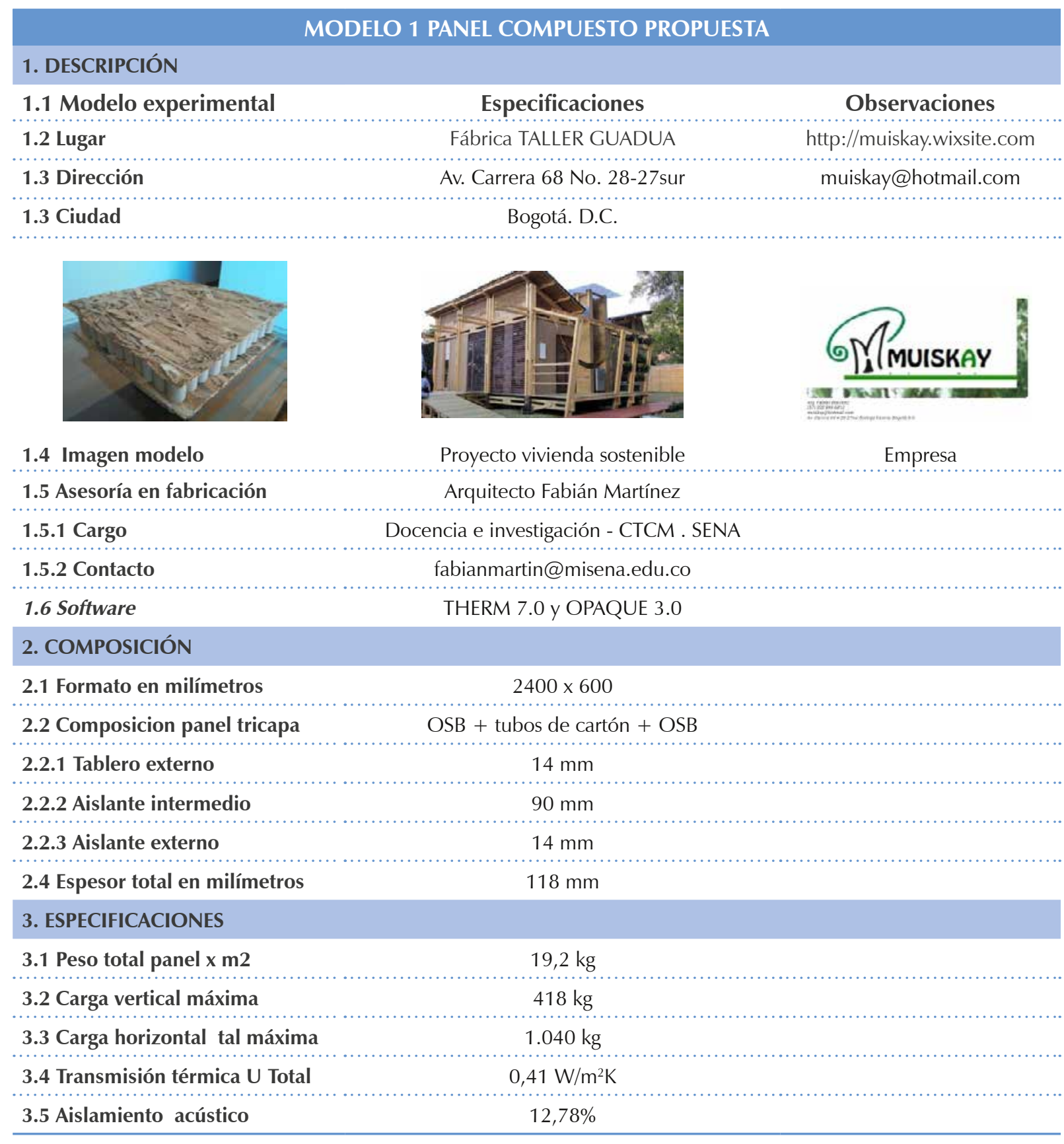

A Tabla 4. Modelo 1: panel compuesto propuesta

Fuente: elaboración propia, 2017

\section{Fabricación}

El procedimiento realizado para su fabricación no es el normalizado (en los países donde se produce) con respecto al adhesivo utilizado ni el tipo de prensado, con él se pretende buscar una alternativa de adhesivos no tóxicos y menor consumo de energía en el prensado.

Todas las hojuelas se sumergieron dentro del adhesivo Carpincol 2500 de Pegatex, y se orientaron de acuerdo con las especificaciones de los tableros OSB, para luego prensar en frío con presión o carga de $30 \mathrm{MPa}(1 \mathrm{MPa}=10,2041$ $\mathrm{kg}-\mathrm{f} / \mathrm{cm}^{2}$ ) durante 3 horas y 40 minutos, luego extraerla con el fin de aplicar otra capa de adhesivo PVA, para nuevamente prensar durante 6 horas y 35 minutos.

Secado: ventilación natural por 48 horas.

Aplicación de barniz de impermeabilización Deva- TARIMEX.

Montaje del aislante con tubos dobles de cartón, reciclado de papel higiénico, pegado a los tableros externos Carpincol 2500.
Armado total del panel compuesto y secado definitivo (Figura 7).

\section{Características}

En la tabla 4 se presentan las principales características del modelo 1, panel compuesto.

\section{Simulación térmica}

Se observan temperaturas (Tabla 5).

\section{Simulación acústica}

La simulación acústica muestra niveles de aislamiento ascendentes constantes en el panel, sin variaciones de aislamiento a 40 decibeles admisibles, de acuerdo con el ruido, y frecuencias entre 50 y $250 \mathrm{~Hz}$, niveles permitidos entre 55 y 65 decibeles; el aislamiento alcanza frecuencias hasta $1.750 \mathrm{~Hz}$ dentro del límite admisible, pero no representa valores diferentes a los que arrojan los referentes, únicamente una mayor constante de absorción en decibeles, promedio de tolerancia auditiva. La estructura de los tableros OSB externos que genera espacios entre virutas permite que una cantidad de ondas sonoras penetre a través de ellas (Tabla 6). 


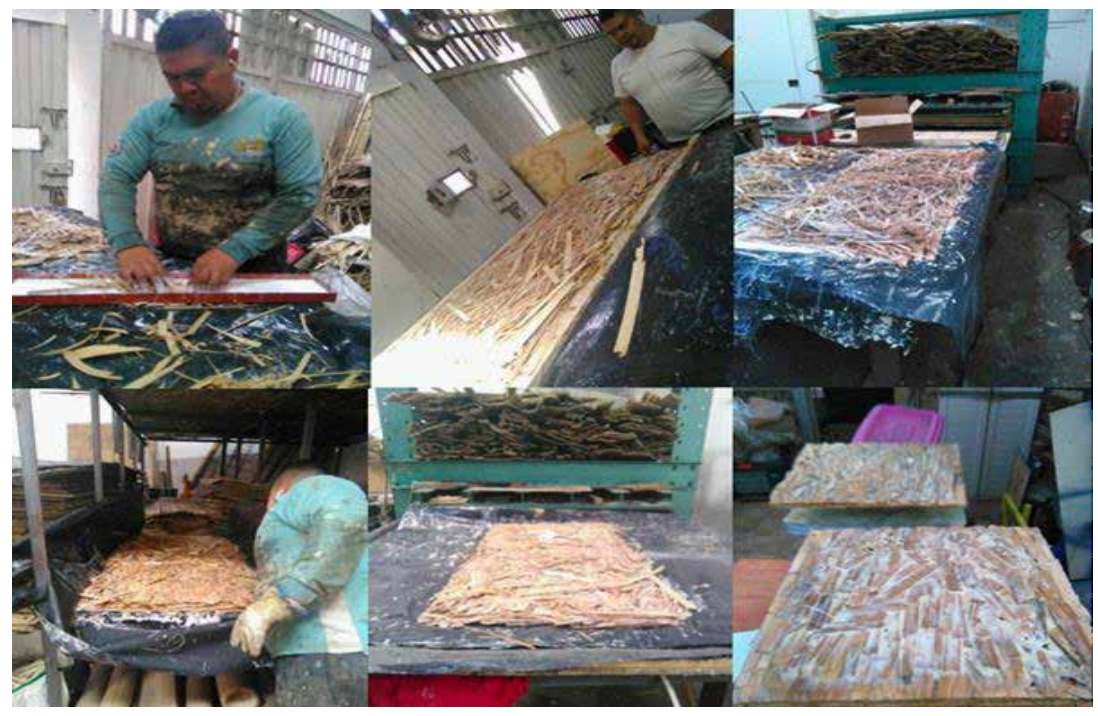

(4) Figura 7. Proceso de fabricación del tablero OSB, empresa Muiskay Fuente: elaboración propia, 2017, CC BY-ND.

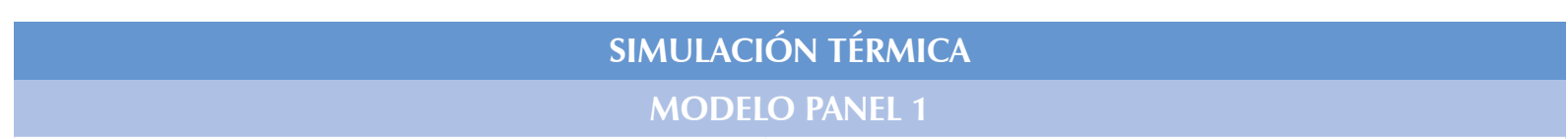

PANEL OSB-RCC-1

OBSERVACIONES
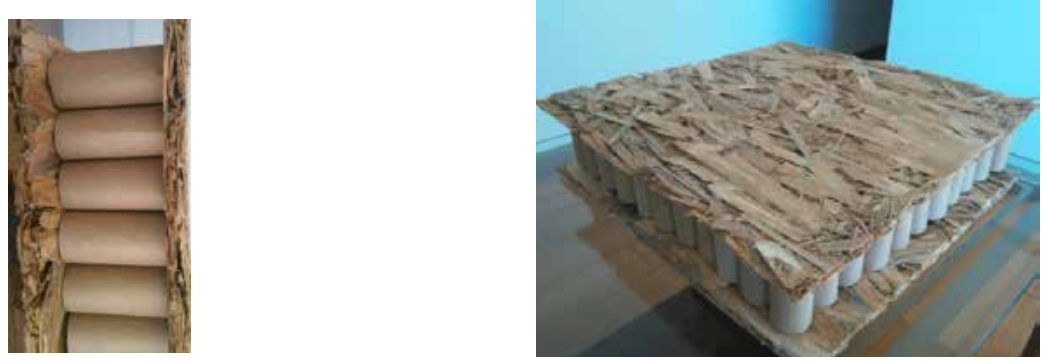

$0,360 \mathrm{~W} / \mathrm{m}^{2} \mathrm{k}$

(1)Osb $+(2)$ Tubos de cartón +(3) osb
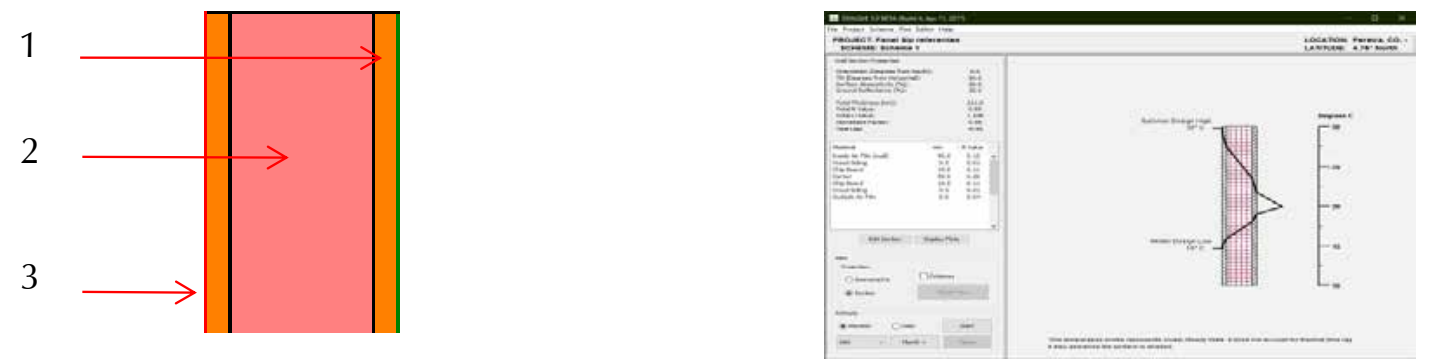

Temperatura mínima media anual $15,8 \stackrel{\circ}{\circ}$
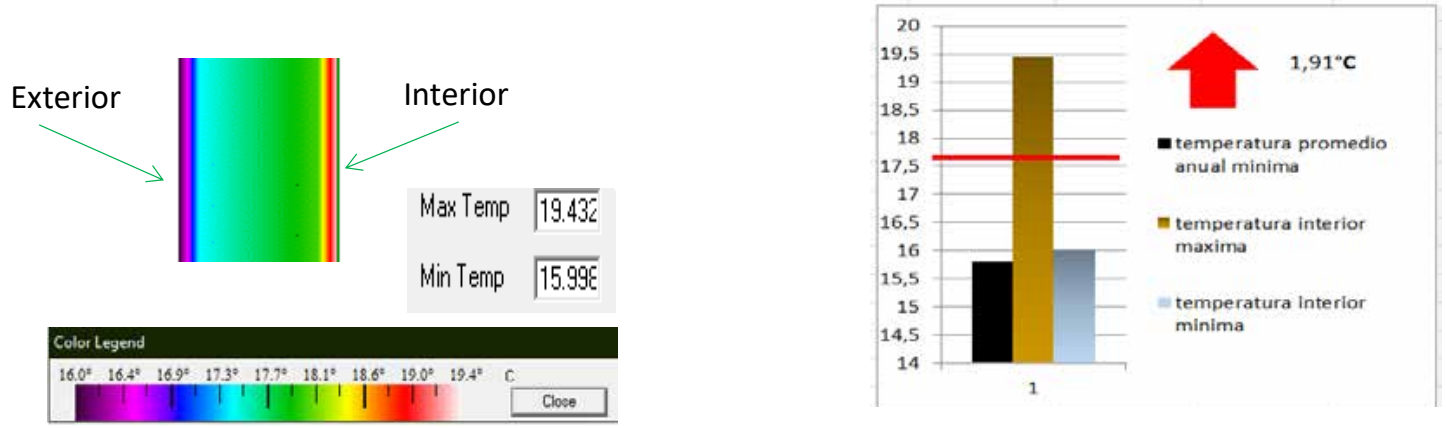

Temperatura máxima media anual $26,3 \circ \mathrm{O} \mathrm{C}$
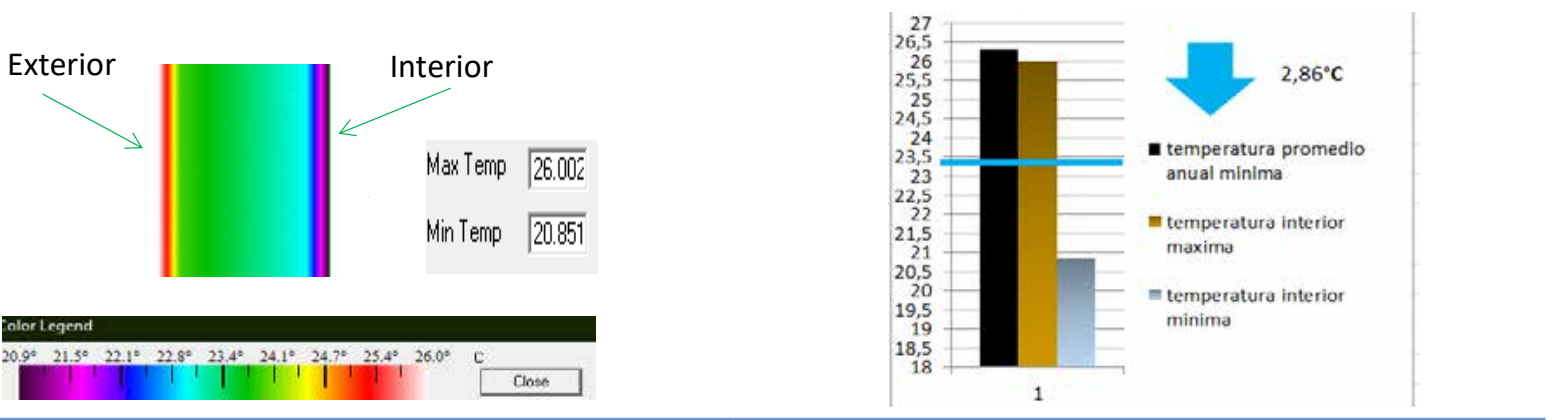


1. DESCRIPCIÓN $\quad$ SIMULACIÓN ACÚSTICA MODELO 1

1.1 Modelo experimental
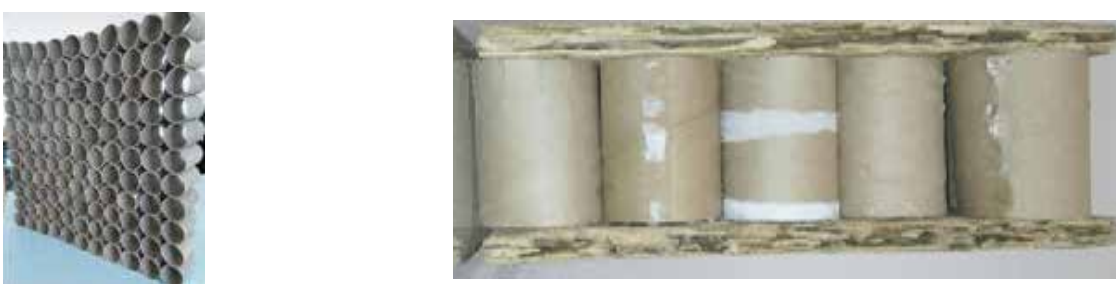

\section{COMPOSICIÓN}

2.1 Formato en metros

2.2 Composición panel tricapa

2.2.1 Espesores en metros

2.2.2 Densidad total

2.2.3 Módulo de Young

2.2.4 Coeficiente de amortiguación

Software. BDKAISLA 3.01

Gráfico de frecuencia vs. decibeles

Obtenido de la base de datos del

Software DBKAISLA 3.01

\section{RESOLUCIÓN 0627 DE 2006}

Máximos permisibles de niveles de emisión de ruido expresados en decibeles $\mathrm{DB}(\mathrm{A})$ para vivienda urbana $=$

vivienda 65 DB(A) Día

$55 \mathrm{DB}(\mathrm{A})$ Noche

\section{$2,40 \times 0,60$}

OSB + tubos de cartón + OSB

$0,014+0,090 m+0,014$

$142,205 \mathrm{~kg} / \mathrm{m}^{3}$

$11 \mathrm{GN} / \mathrm{m}^{2}$

0,11

Tabla 6. Simulación acústica Modelo 1

Fuente: elaboración propia, 2017.

Índice $\mathrm{D}$, diferencia de niveles o aislamiento bruto: $\mathrm{D}=\mathrm{L} 1-\mathrm{L} 2$

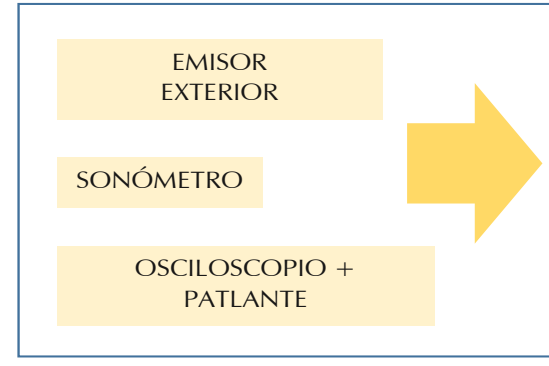

L1 el nivel de presión sonora medido en $\mathrm{dB}$ en el recinto emisor

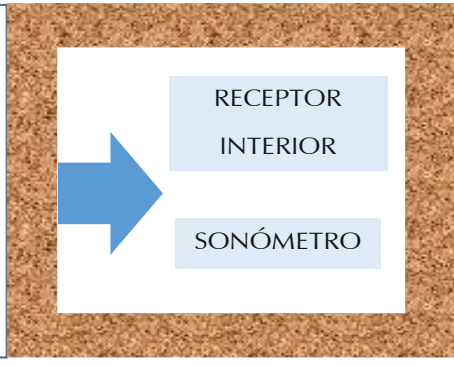

L2 el nivel de presión sonora medido en $\mathrm{dB}$ en el recinto receptor
(A) Figura 8. Procedimiento de simulación acústica en laboratorio

Fuente: elaboración propia, 2017, CC BY.

$\rightarrow$ Figura 9. Equipos utilizados para el Laboratorio de Acústica de los paneles propuestos.

Fuente: elaboración propia, 2017, CC BY.
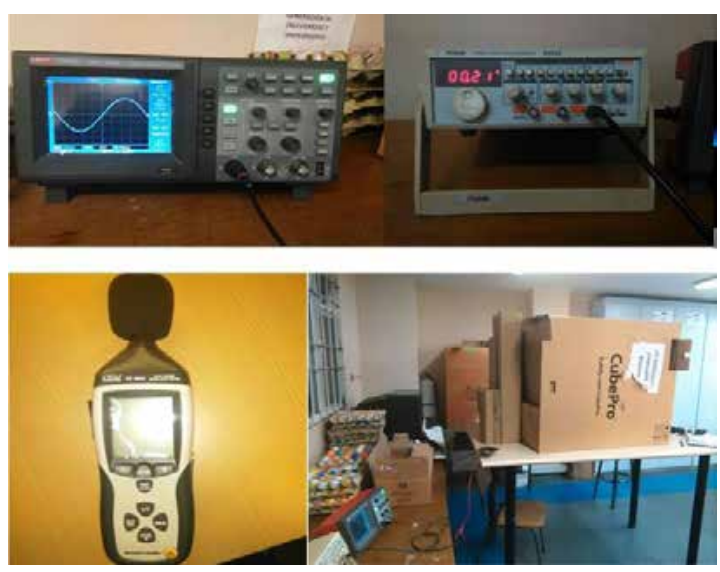

100

\section{Pruebas de laboratorio}

Acústica. La medición de absorción acústica se realizó en el laboratorio de la Universidad Católica de Colombia, simulando un espacio interior cerrado con una caja de cartón de un metro cúbico como volumen, ubicando en uno de sus lados el modelo experimental. Para la medición interna se utilizó un sonómetro que tomó la lectura de los decibeles, de acuerdo con el ruido aplicado exterior, en frecuencias de menor a través de un amplificador generador de ruido que indica la frecuencia como base de datos (Figuras 8 y 9).

En la Tabla 7 se muestran los resultados obtenidos, los cuales reflejan frecuencia exterior, ruido exterior e interno, y diferencia, para hallar finalmente el porcentaje promedio de aislamiento acústico (Figura 10), lo que arroja una diferencia de 11,88 db, un resultado de porcentaje de absorción del 18 al 20\%, que es representativo si se tiene en cuenta que en una vivienda intervienen adicionalmente elementos que configuran los espacios como cielo rasos, cubiertas, ventanerías, pisos, etc. 


\begin{tabular}{|c|c|c|c|}
\hline \multicolumn{4}{|c|}{ MODELO 1} \\
\hline $\begin{array}{c}\text { Ruido exterior en } \\
\text { frecuencia HZ }\end{array}$ & $\begin{array}{l}\text { Ruido exterior } \\
\text { en Db }\end{array}$ & $\begin{array}{c}\text { Ruido interno } \\
\text { en Db }\end{array}$ & Diferencia en Db \\
\hline 1730 & 96,4 & 78,4 & 18 \\
\hline 1450 & 90,2 & 77,5 & 12,7 \\
\hline 1003 & 84,4 & 70,2 & 14,2 \\
\hline 921 & 77,7 & 69,8 & 7,9 \\
\hline 735 & 69,4 & 63,1 & 6,3 \\
\hline 669 & 67,2 & 56,3 & 10,9 \\
\hline 367 & 59,6 & 48,6 & 11 \\
\hline 226 & 55,4 & 41,4 & 14 \\
\hline \multicolumn{3}{|c|}{ Valor promedio de aislamiento acústico } & 11,875 \\
\hline
\end{tabular}

Tabla 7. Nivel de ruido exterior frente a nivel interior y porcentaje de absorción

Fuente: elaboración propia, 2017.

\begin{tabular}{|c|c|c|}
\hline \multicolumn{3}{|c|}{ RESULTADOS DE RESISTENCIA FÍSICA DEL MODELO 1} \\
\hline Dimensiones probeta & Unidad & Cantidad \\
\hline Área & $m^{2}$ & 0,0625 \\
\hline Espesor & $\mathrm{ml}$ & 0,118 \\
\hline Peso & $\mathrm{kg}$ & 1,2 \\
\hline \multicolumn{3}{|l|}{ Materiales } \\
\hline 1. Tableros madera OSB guadua & Unidad & 2 \\
\hline Densidad & $\mathrm{kg} / \mathrm{m}^{3}$ & 738 \\
\hline 2. Tubos dobles de cartón tubular & Diámetro & 5 \\
\hline Densidad & $\mathrm{kg} / \mathrm{m}^{3}$ & 22,32 \\
\hline \multicolumn{3}{|l|}{ Aplicación de la carga } \\
\hline $\begin{array}{c}\text { Superficie de presión } \\
\text { de la prensa }\end{array}$ & $\mathrm{m}^{2}$ & 0,0177 \\
\hline Carga horizontal & $\mathrm{kg}$ & 1.040 \\
\hline Carga vertical & $\mathrm{kg}$ & 418 \\
\hline
\end{tabular}

\& Tabla 8. Prueba de resistencia horizontal y vertical

Fuente: elaboración propia, 2017.

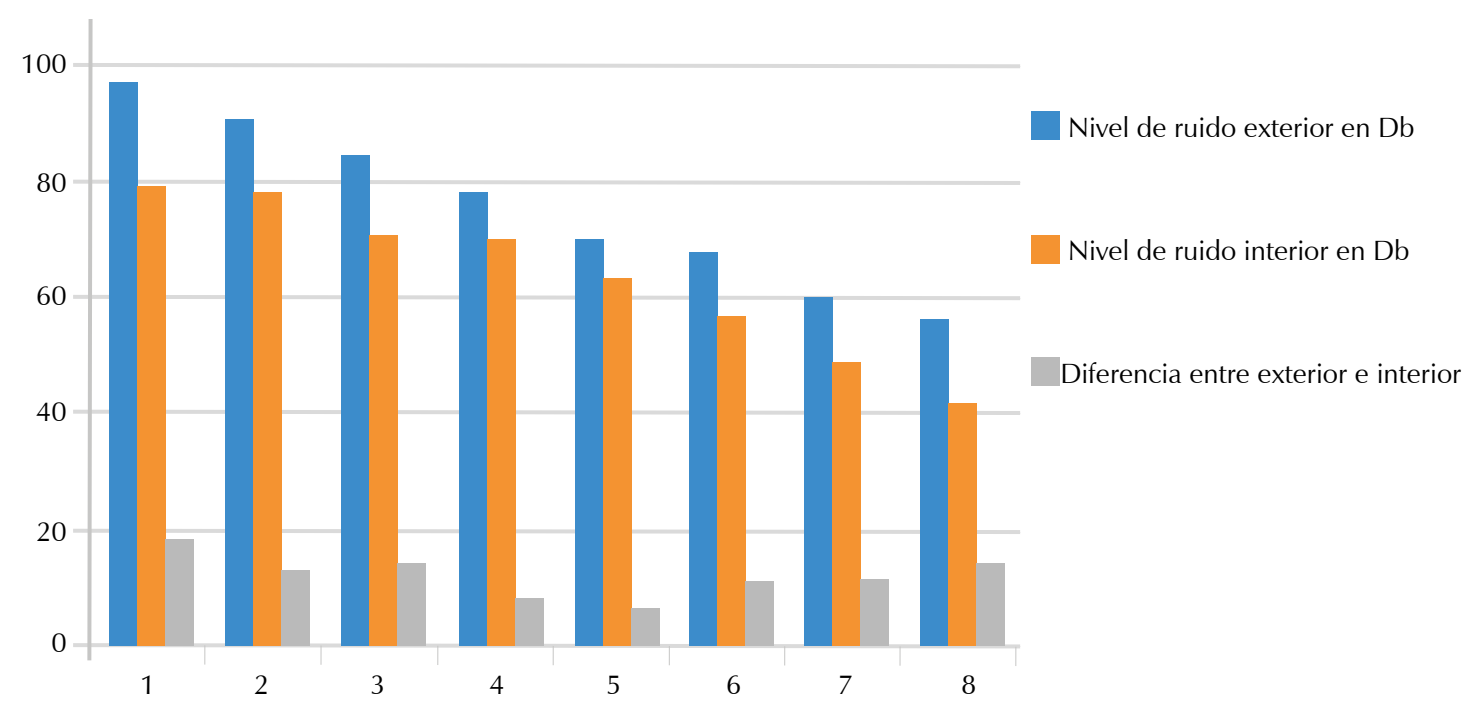

(4) Figura 10. Resultados obtenidos del aislamiento interno frente a externo

Fuente: elaboración propia, 2017.
Pruebas de resistencia a compresión. La máquina universal de ensayos de tensión y compresión de una sola columna (Figura 11) fue utilizada para someter a compresión el panel modelo, que presentó resistencia al límite de la deformación sin rotura.

Los valores arrojados, tanto en carga vertical como horizontal, se encuentran dentro de los descritos por los referentes seleccionados del mercado en la construcción mundial. El panel funciona como un elemento no directamente estructural y su resistencia a esfuerzos está ligada a su función como envolvente (Tabla 8).

\section{Modelo 2}

Materiales

Virutas o astillas de fibra de guadua como residuo de la elaboración de tablillas, canoas, esterillas y otros cortes que se comercializan como elementos de construcción, obtenido a través de la empresa Induguadua, Armenia-La Tebaida. 
Adhesivo para la formación de los tableros: urea formaldehído.

Aislante: triple lámina de cartón panal o Honeycomb board (Tabla 9) $\mathrm{E}=31 \mathrm{~mm} \mathrm{c/u}$ Fabricante Perlad SAS.

Adhesivo Carpincol 2500 - Pegatex para la unión de las tres capas.

Barniz (uretano base solvente transparente) para exteriores en madera.

\section{Fabricación}

Se realiza siguiendo los lineamientos principales utilizados actualmente por los fabricantes (Apa's Corporate, 2015), con la única diferencia de cambiar la viruta de pino y abeto por la viruta de guadua (Figura 12).
Selección de materia prima de madera guadua en hojuela o viruta $(E=0,6 / 1,2 \mathrm{~mm})$ con dimensiones de 10 a $20 \mathrm{~mm}$ de ancho por 15 a $30 \mathrm{~mm}$ de largo, apta para la fabricación del tablero OSB, con humedad a $5 \%$ a través de horno de convección.

Realización del encolado de las partículas con resina urea-formaldehído cuyas especificaciones eran densidad $1270 \mathrm{~kg} / \mathrm{m}^{3} ; 65 \%$ sólidos, formando el tablero en capas el cual se ingresa a la prensa mono-piso a una temperatura de $210^{\circ} \mathrm{C}$, presión específica de $42 \mathrm{~kg} / \mathrm{cm}^{2}$ y un tiempo de prensado de $4 \mathrm{~min}$. Finalmente se realizan los ensayos físico-mecánicos en una máquina universal, donde se midieron las propiedades de enlace interno, y los módulos de elasticidad y de rotura.

\begin{tabular}{|c|c|c|}
\hline & MODELO PANEL COMPUESTO PROPUESTA & \\
\hline 1. DESCRIPCIÓN & MODELO 2 & OBSERVACIONES \\
\hline \multicolumn{3}{|c|}{ 1.1 Modelo experimental } \\
\hline 1.2 Lugar & Planta PRIMADERA & http://www.primadera.com/ \\
\hline 1.3 Dirección & Carretera Central Norte km 49 - Vereda la Aurora & \\
\hline 1.3 Ciudad & Gachancipá - Cundinamarca & \\
\hline
\end{tabular}
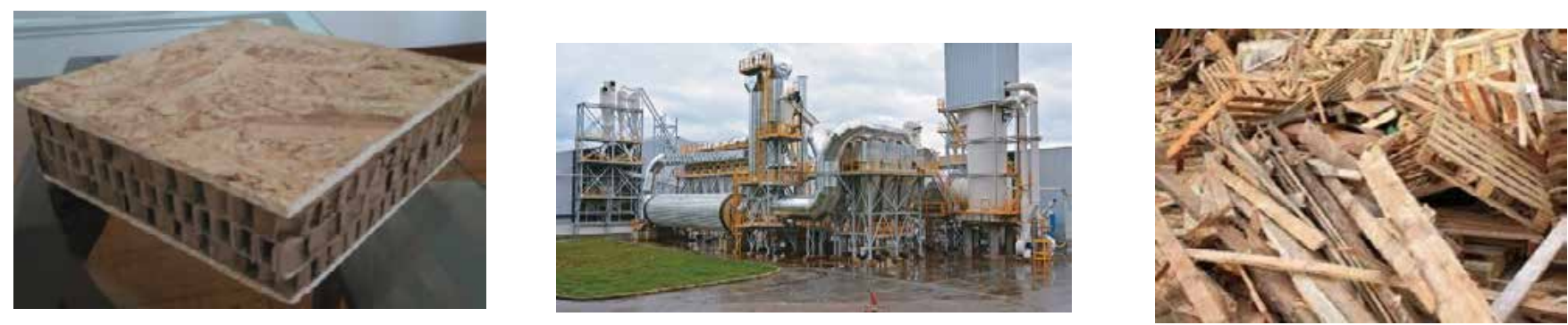

\begin{tabular}{|c|c|c|}
\hline 1.4 Imagen modelo pruebas & Fabrica PRIMADERA SAS & "Madera Urbana" \\
\hline 1.5 Asesoría en fabricación & Ingeniero. José A. Gutiérrez & \\
\hline 1.5.1 Cargo & Jefe de Procesos e Investigación & \\
\hline 1.5.2 Contacto & jogutierrez@pimadera.com & \\
\hline 1.6 Software & THERM 7.0 Y OPAQUE 3.0 & \\
\hline \multicolumn{3}{|l|}{ 2. COMPOSICIÓN } \\
\hline 2.1 Formato en milímetros & $2400 \times 1200$ & \\
\hline 2.2 Composición panel tricapa & OSB + Lámina Cartón Panal + OSB & \\
\hline 2.2.1 Tablero externo & $11 \mathrm{~mm}$ & \\
\hline 2.2.2 Aislante intermedio & $100 \mathrm{~mm}$ & \\
\hline 2.2.3 Aislante externo & $11 \mathrm{~mm}$ & \\
\hline 2.4 Espesor total en milímetros & $122 \mathrm{~mm}$ & \\
\hline \multicolumn{3}{|l|}{ 3. ESPECIFICACIONES } \\
\hline 3.1 Peso total panel $\mathrm{x} \mathrm{m}^{2}$ & $21,92 \mathrm{~kg}$ & \\
\hline 3.2 Carga vertical máxima & $1.970 \mathrm{~kg}$ & \\
\hline 3.3 Carga horizontal tal máxima & $518 \mathrm{~kg}$ & \\
\hline 3.4 Transmisión térmica $U$ total & $0,34 \mathrm{~W} / \mathrm{m}^{2} \mathrm{~K}$ & \\
\hline 3.7 Aislamiento acústico & $13,13 \%$ & \\
\hline
\end{tabular}

(4) Tabla 9. Modelo 2, paneles. Ficha técnica

Fuente: elaboración propia, 2017. 


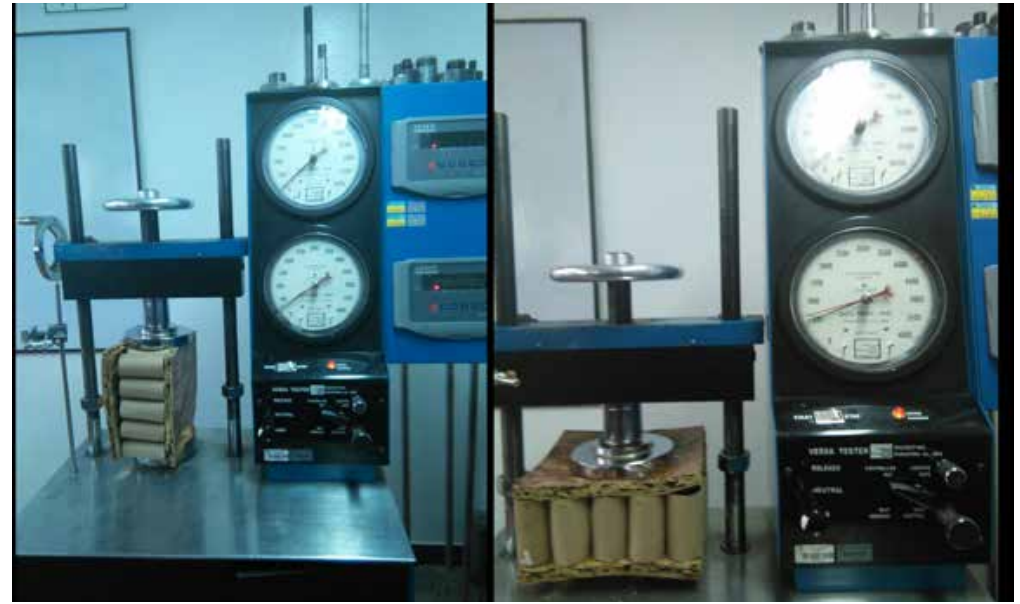

(A) Figura 11. Equipos utilizados (prensa hidráulica) para pruebas de resistencia de carga horizontal y carga vertical

Fuente: elaboración propia, 2017, CC BY.

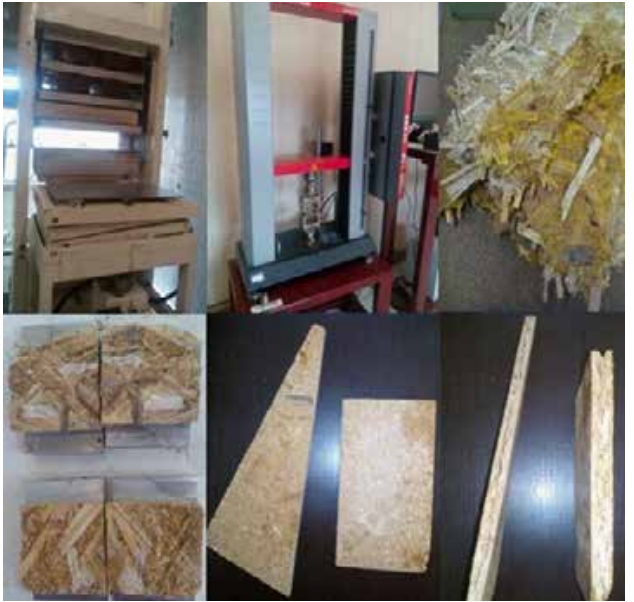

A Figura 12. Proceso de fabricación de probetas y tablero

Fuente: Primadera SAS, 2017.

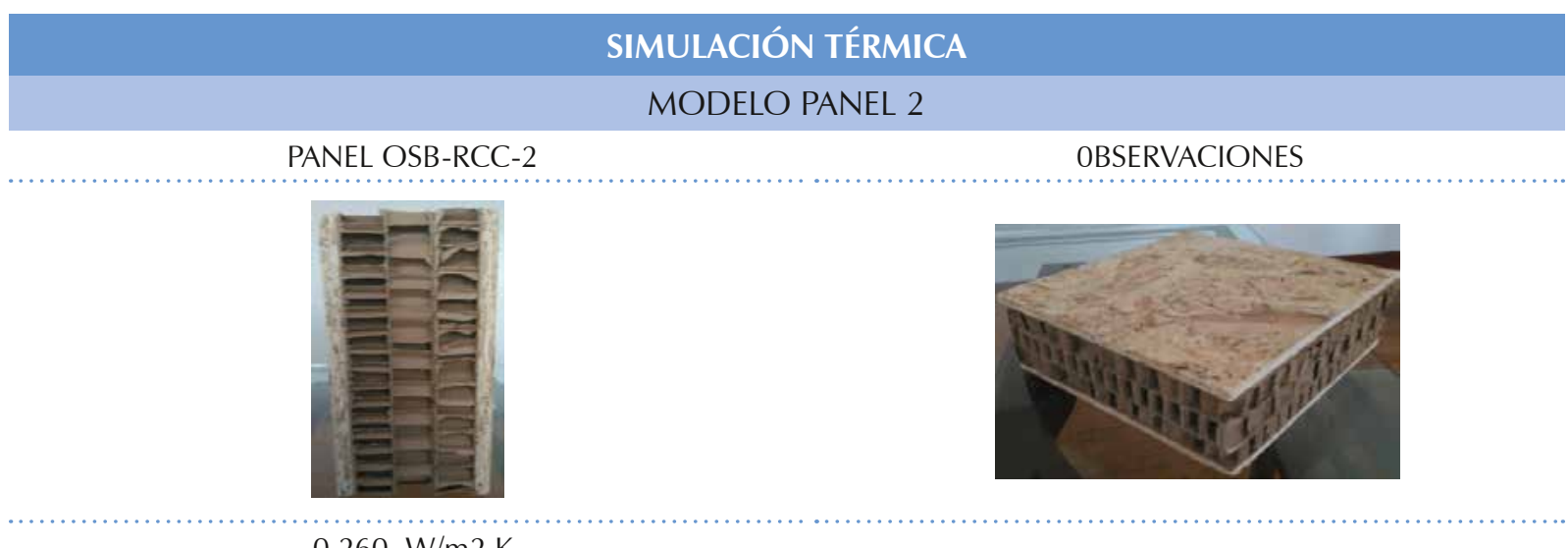

$0,260 \mathrm{~W} / \mathrm{m} 2 \mathrm{~K}$

(1)Osb + (2) Láminas cartón panal + (3)Osb

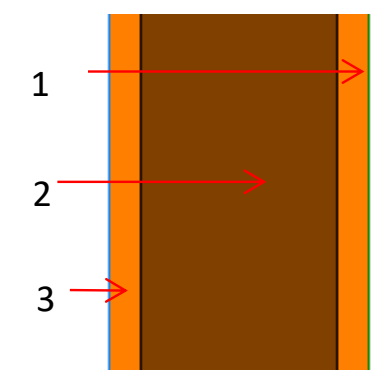

Temperatura mínima media anual 15,8 드
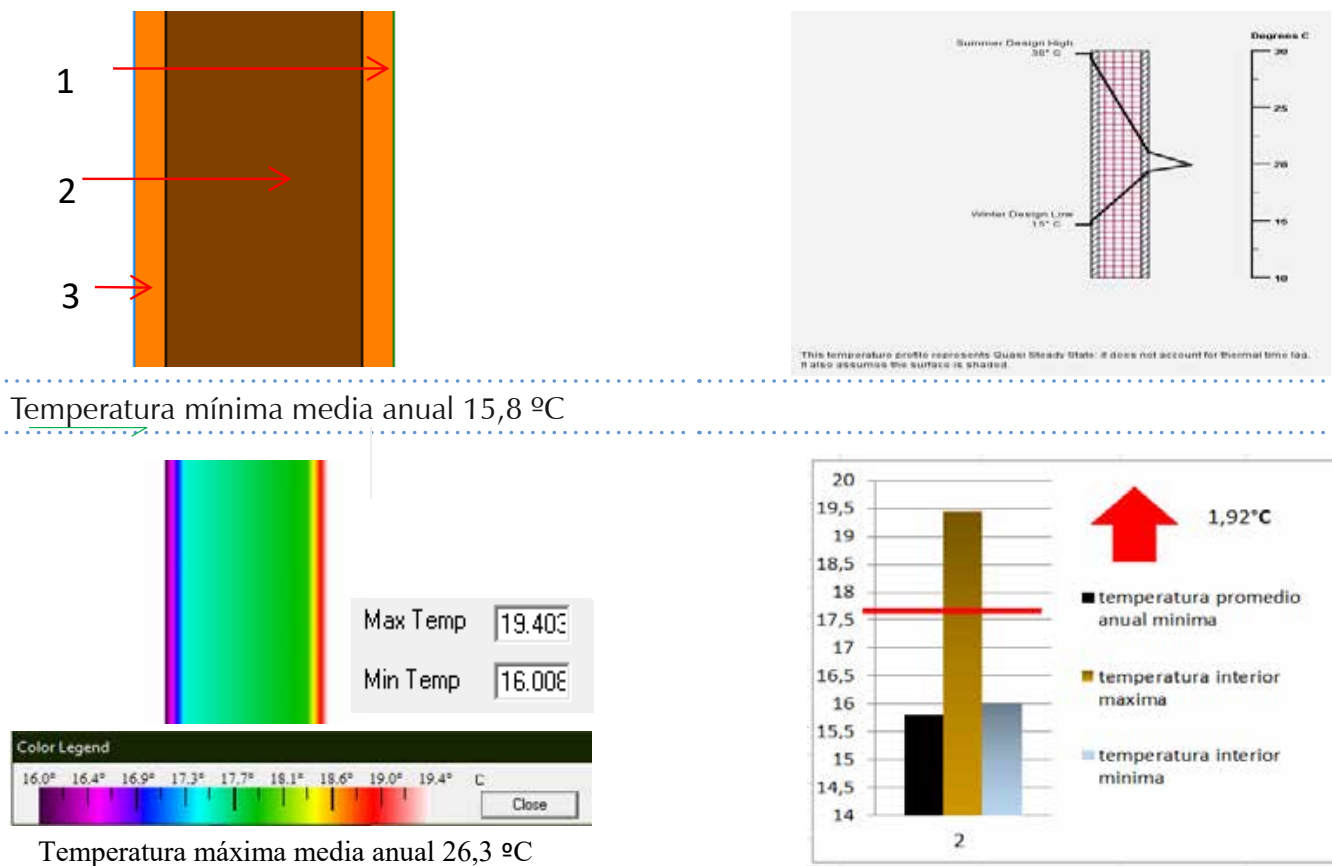

Temperatura máxima media anual 26,3 으
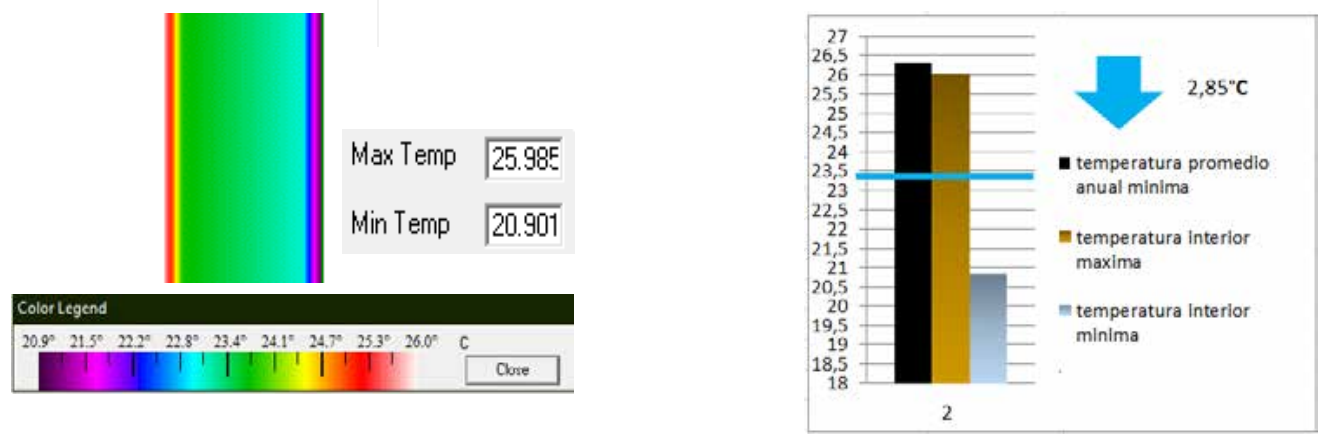
Debido a la tecnología utilizada para este caso, el tablero obtenido está más cerca de ser un tablero aglomerado que uno OSB. Por tanto, los resultados presentaron propiedades físico-mecánicas altas, como expertos en tableros aglomerados.

\section{Características (Tabla 9)}

\section{Simulación térmica}

Se observan temperaturas promedio internas similares al Modelo 1, en las mínimas exteriores de $15,8^{\circ} \mathrm{C}$, con un aumento de $1,92^{\circ} \mathrm{C}$, y en las máximas promedio de disminución de $2,85^{\circ} \mathrm{C}$, lo cual obedece básicamente al buen aislamiento térmico producido por el vacío existente entre las celdas del sistema panal de abejas en cartón reciclado; esto representa valores importantes de control interno de la temperatura, como parte fundamental en el confort habitacional de la edificación (Tabla 10).

\section{Simulación acústica}

La simulación acústica (Tabla 11) muestra niveles de aislamiento ascendentes constantes en el panel, sin variaciones de aislamiento a 40 decibeles admisibles, de acuerdo con el ruido, y frecuencias entre 50 y $250 \mathrm{~Hz}$. Dentro de los niveles permitidos entre 55 y 65 decibeles, el aislamiento alcanza frecuencias hasta $1.750 \mathrm{~Hz}$ dentro del límite admisible, pero que no representan valores diferentes a los que arrojan los referentes, únicamente una mayor constante de absorción en decibeles promedio de tolerancia auditiva.

\section{Pruebas laboratorio}

Acústica. En la Tabla 12 se muestran los resultados obtenidos de absorción promedio de 13,14 Db y porcentaje promedio de aislamiento acústico del 15 al $20 \%$, porcentaje representativo que obedece básicamente a la densidad y compactación de los tableros OSB que aumenta su calidad de aislamiento.

SIMULACIÓN ACÚSTICA MODELO 2
1. DESCRIPCIÓN
1.1 Modelo experimental

1.3 Imagen
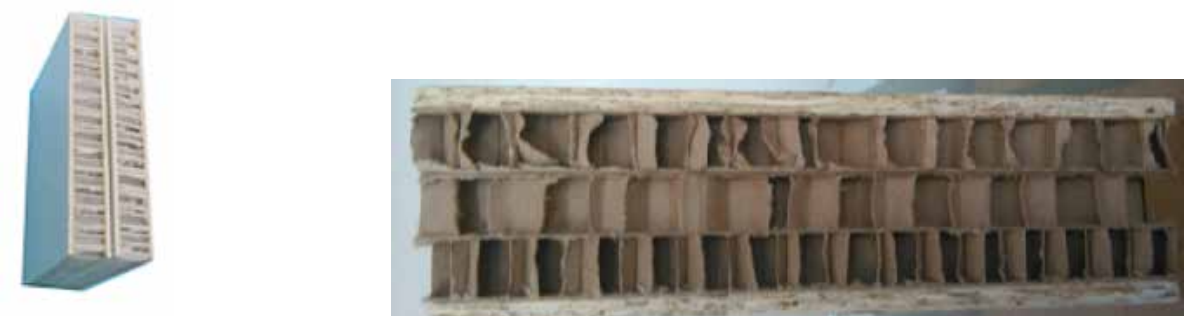

\begin{tabular}{|c|c|}
\hline 2. COMPOSICIÓN & \\
\hline 2.1 Formato en metros & $2,40 \times 1,20$ \\
\hline 2.2 Composición panel tricapa & OSB + cartón hexagonal + OSB \\
\hline 2.2.1 Espesores en metros & $0,012+0,090 m+0,012=114$ \\
\hline 2.2.2 Densidad total & $155,6 \mathrm{~kg} / \mathrm{m}^{3}$ \\
\hline 2.2.3 Módulo de Young & $11 \mathrm{GN} / \mathrm{m}^{2}$ \\
\hline 2.2.4 Coeficiente de amortiguación & 0,11 \\
\hline
\end{tabular}

Software. BDKAISLA 3.01

Gráfico de frecuencia vs. decibeles

Obtenido de la base de datos del

Software DBKAISLA 3.01

RESOLUCIÓN 0627 DE 2006

Máximos permisibles de niveles de emisión de ruido expresados en decibeles $\mathrm{DB}(\mathrm{A})$ para vivienda urbana $=$ vivienda 65 DB(A) Día

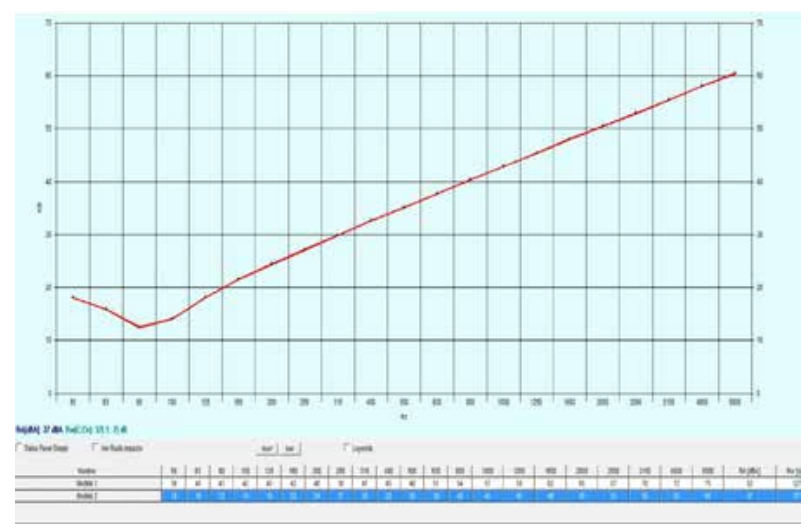

$55 \mathrm{DB}(\mathrm{A})$ noche

Tabla 11. Simulación acústica Panel 2

Fuente: elaboración propia, 2017

\begin{tabular}{|c|c|c|c|c|c|c|c|c|c|c|c|c|c|c|c|c|c|c|c|c|c|}
\hline (1) & 80 & 100 & 165 & & $\mathbb{W}$ & 20 & 315 & 40 & $\mathbb{W}$ & 60 & 80 & 100 & 1200 & 100 & 3000 & 2600 & 310 & 1000 & 500 & BA $(606)$ & Rul $(00)$ \\
\hline$\sqrt{11}$ & $\bar{u}$ & 12 & B & in & 40 & 18 & 4 & 48 & (1) & y & 4 & 7 & $\overline{98}$ & M & y & $\overline{\theta 11}$ & 77 & 77 & $\pi$ & 12 & $\overline{4}$ \\
\hline
\end{tabular}


Resistencia a compresión. Al someter el panel a compresión, el panel modelo presentó resistencia al límite de la deformación sin rotura. Los valores arrojados, tanto en carga vertical de $518 \mathrm{~kg}$, como horizontal de $1970 \mathrm{~kg}$, se encuentran dentro de los valores admisibles en los referentes estudiados (Tabla 13). Se presentó mayor resistencia y menos deformación de los tableros, pero hundimiento del sistema aislante interno en cartón, con un aplastamiento en la carga horizontal y mayor resistencia en la carga vertical.

\section{Evaluación comparativa de resultados}

La evaluación de los resultados se realizó comparando las simulaciones térmicas y acústicas, tanto de los referentes como de los modelos experimentales fabricados, indicando su eficiencia en nivel de confort y permitiendo una medición objetiva y concluyente.

\section{Aislamiento térmico}

En el tema de aislamiento térmico, los valores obtenidos (Tabla 14) indican que tanto referentes como modelos experimentales mantienen una relativa homogeneidad en los niveles de confort interno. Se destacan los ubicados entre rangos de temperatura mínima de 17,71 y $21,9{ }^{\circ} \mathrm{C}$ como el mejor (Modelo 2), y entre 17,38 y $22,38{ }^{\circ} \mathrm{C}$ como el más desfavorable (LP SIP, Chile).

\section{Aislamiento acústico}

Los niveles de aislamiento, según la norma de decibeles admisibles, indican que el Modelo 2 mantiene iguales condiciones que el referente 1 de acuerdo con lo presentado en la Tabla 14, aunque dentro de los referentes existen aislamientos con frecuencias superiores, producto de aislantes más densos pero derivados del petróleo. Asimismo, entre los modelos experimentales (Tabla 15) se observan mejores niveles en el Modelo 2, debido a la densidad del cartón y el hermetismo de la composición hexagonal del cartón Honeycomb.

\begin{tabular}{|c|c|c|c|}
\hline \multicolumn{4}{|c|}{ MODELO 2} \\
\hline $\begin{array}{c}\text { Ruido exterior en } \\
\text { frecuencia } \mathrm{HZ}\end{array}$ & $\begin{array}{l}\text { Ruido exterior en } \\
\text { Db }\end{array}$ & Ruido interno en Db & Diferencia en Db \\
\hline 1730 & 96,4 & 76,8 & 19,6 \\
\hline 1450 & 90,2 & 75,5 & 14,7 \\
\hline 1003 & 84,4 & 68,4 & 16 \\
\hline 921 & 77,7 & 62,6 & 15,1 \\
\hline 735 & 69,4 & 57,6 & 11,8 \\
\hline 669 & 67,2 & 55,6 & 11,6 \\
\hline 367 & 59,6 & 51,4 & 8,2 \\
\hline 226 & 55,4 & 47,3 & 8,1 \\
\hline \multicolumn{3}{|c|}{ Valor promedio de aislamiento acústico } & 13,1375 \\
\hline
\end{tabular}

Tabla 12. Nivel de ruido exterior frente a nivel interior del panel y su porcentaje de absorción

Fuente: elaboración propia, 2017.

\begin{tabular}{|c|c|c|c|}
\hline \multicolumn{4}{|c|}{ RESULTADOS DE RESISTENCIA FÍSICA DEL MODELO 2} \\
\hline Dimensiones probeta & Unidad & Cantidad & Observación \\
\hline Área & $\mathrm{m}^{2}$ & 0,0625 & \\
\hline Espesor & $\mathrm{ml}$ & 0,122 & \\
\hline \multicolumn{4}{|l|}{ Materiales } \\
\hline 1. Tableros madera OSB guadua & Unidad & 2 & \\
\hline Densidad & $\mathrm{kg} / \mathrm{m}^{3}$ & 697 & \\
\hline 2. Cartón panal Honeycomb & Diámetro & 5 & \\
\hline Densidad & $\mathrm{kg} / \mathrm{m}^{3}$ & 27,4 & \\
\hline \multicolumn{4}{|l|}{ Aplicación de la carga } \\
\hline $\begin{array}{l}\text { Superficie de presión } \\
\text { de la prensa }\end{array}$ & $\mathrm{m}^{2}$ & 0,0177 & \\
\hline Carga horizontal & $\mathrm{kg}$ & 1.970 & \\
\hline Carga vertical & $\mathrm{kg}$ & 518 & \\
\hline
\end{tabular}

Tabla 13. Prueba de resistencia horizontal y vertical del Modelo 2

Fuente: elaboración propia, 2017. 


\begin{tabular}{|c|c|c|c|c|c|c|c|}
\hline \multicolumn{8}{|c|}{ RESULTADOS SIMULACIONES TÉRMICAS. SOFTWARE THERM 7,0 } \\
\hline SIMULACIÓN TÉRMICA & Unidad & Referente 1 & Referente 2 & Referente 3 & Referente 4 & Modelo 1 & Modelo 2 \\
\hline & & THERMO CHIP & HEMSEC SIPS & THE WALL & LP SIP & MUISKAY & PRIMADERA \\
\hline Espesor panel tricapa & $\mathrm{mm}$ & 150 & 110 & 110 & 95 & 118 & 122 \\
\hline Valor U & $\mathrm{W} / \mathrm{m} 2 \mathrm{~K}$ & 0,36 & 0,26 & 0,364 & 0,515 & 0,41 & 0,34 \\
\hline Valor $R=1 / U$ & $\mathrm{~K}-\mathrm{m} 2 / \mathrm{W}$ & 2,78 & 3,85 & 2,75 & 1,94 & 2,44 & 2,94 \\
\hline $\begin{array}{l}\text { Temperatura promedio mínima } \\
\text { exterior } 15,8\end{array}$ & ${ }^{\circ} \mathrm{C}$ & 15,8 & 15,8 & 15,8 & 15,8 & 15,8 & 15,8 \\
\hline Temperatura interior máxima & ${ }^{\circ} \mathrm{C}$ & 18,861 & 18,759 & 18,925 & 18,411 & 19,432 & 19,402 \\
\hline Temperatura interior mínima & ${ }^{\circ} \mathrm{C}$ & 16,196 & 16,233 & 16,175 & 16,355 & 15,996 & 16,006 \\
\hline Diferencia promedio interior & ${ }^{\circ} \mathrm{C}$ & 2,665 & 2,526 & 2,75 & 2,056 & 3,436 & 3,396 \\
\hline Diferencia máxima interior & ${ }^{\circ} \mathrm{C}$ & 3,061 & 2,959 & 3,125 & 2,611 & 3,632 & 3,602 \\
\hline Diferencia mínima interior & ${ }^{\circ} \mathrm{C}$ & 0,396 & 0,433 & 0,375 & 0,555 & 0,196 & 0,206 \\
\hline $\begin{array}{l}\text { Promedio temperatura int. } \\
\text { respecto al exterior }\end{array}$ & ${ }^{\circ} \mathrm{C}$ & 1,729 & 1,696 & 1,75 & 1,583 & 1,914 & 1,904 \\
\hline $\begin{array}{l}\text { Temperatura promedio máxima } \\
\text { exterior } 26,3\end{array}$ & ${ }^{\circ} \mathrm{C}$ & 26,3 & 26,3 & 26,3 & 26,3 & 26,3 & 26,3 \\
\hline Temperatura interior máxima & ${ }^{\circ} \mathrm{C}$ & 25,702 & 25,649 & 25,736 & 25,466 & 26,002 & 25,985 \\
\hline Temperatura interior mínima & ${ }^{\circ} \mathrm{C}$ & 21,702 & 21,86 & 21,611 & 22,382 & 20,851 & 20,901 \\
\hline Diferencia promedio interior & ${ }^{\circ} \mathrm{C}$ & 4 & 3,789 & 4,125 & 3,084 & 5,151 & 5,084 \\
\hline Diferencia máxima interior & ${ }^{\circ} \mathrm{C}$ & 0,598 & 0,651 & 0,564 & 0,834 & 0,298 & 0,315 \\
\hline Diferencia mínima interior & ${ }^{\circ} \mathrm{C}$ & 4,598 & 4,44 & 4,689 & 3,918 & 5,449 & 5,399 \\
\hline $\begin{array}{l}\text { Promedio temperatura int. } \\
\text { respecto al exterior }\end{array}$ & ${ }^{\circ} \mathrm{C}$ & 2,598 & 2,546 & 2,627 & 2,376 & 2,874 & 2,857 \\
\hline
\end{tabular}

\begin{tabular}{|c|c|c|c|c|c|c|c|}
\hline CONCLUSIONES. RESULTADOS & Unidad & Referente 1 & Referente 2 & Referente 3 & Referente 4 & Modelo 1 & Modelo 2 \\
\hline & & THERMO CHIP & HEMSEC SIPS & THE WALL & LP SIP & MUISKAY & PRIMADERA \\
\hline $\begin{array}{l}\text { Temperatura promedio mínima } \\
\text { exterior } 15,8\end{array}$ & ${ }^{\circ} \mathrm{C}$ & 15,8 & 15,8 & 15,8 & 15,8 & 15,8 & 15,8 \\
\hline $\begin{array}{l}\text { Promedio temperatura respecto al } \\
\text { exterior sube }\end{array}$ & ${ }^{\circ} \mathrm{C}$ & 1,73 & 1,7 & 1,75 & 1,58 & 1,91 & 1,91 \\
\hline $\begin{array}{l}\text { Temperatura promedio máxima } \\
\text { exterior } 26,3\end{array}$ & ${ }^{\circ} \mathrm{C}$ & 26,3 & 26,3 & 26,3 & 26,3 & 26,3 & 26,3 \\
\hline $\begin{array}{l}\text { Promedio temperatura respecto al } \\
\text { exterior baja }\end{array}$ & ${ }^{\circ} \mathrm{C}$ & 2,6 & 2,55 & 2,63 & 2,37 & 2,88 & 2,86 \\
\hline
\end{tabular}

(A) Tabla 14. Resultados simulaciones térmicas.

Fuente: elaboración propia, 2017.

\begin{tabular}{|c|c|c|c|c|c|c|c|}
\hline \multicolumn{8}{|c|}{ RESULTADOS SIMULACIONES ACÚSTICAS } \\
\hline SIMULACIÓN ACÚSTICA & Unidad & Referente 1 & Referente 2 & Referente 3 & Referente 4 & Modelo 1 & Modelo 2 \\
\hline & & $\begin{array}{l}\text { THERMO } \\
\text { CHIP }\end{array}$ & HEMSEC SIPS & THE WALL & LP SIP & MUISKAY & PRIMADERA \\
\hline Espesor panel tricapa & $\mathrm{mm}$ & 150 & 110 & 110 & 95 & 118 & 122 \\
\hline Aislante densidad & $\mathrm{kg} / \mathrm{m}^{3}$ & 30 & 30 & $15 \mathrm{~K}$ & 15 & 22,32 & 27,4 \\
\hline Tableros densidad & $\mathrm{kg} / \mathrm{m}^{3}$ & 670,00 & 640,00 & 640,00 & $610 \mathrm{Kg} / \mathrm{m}^{3}$ & 548,00 & 738,00 \\
\hline \multirow{2}{*}{ Niveles de aislamiento } & $55 \mathrm{db}$ & $55 \mathrm{db}$ & $55 \mathrm{db}$ & $55 \mathrm{db}$ & $55 \mathrm{db}$ & $55 \mathrm{db}$ & $55 \mathrm{db}$ \\
\hline & hz & 3.150 & 4.500 & 4.450 & 4.700 & 980 & s150 \\
\hline
\end{tabular}

(A) Tabla 15. Resultados de simulaciones acústicas

Fuente: elaboración propia, 2017. 

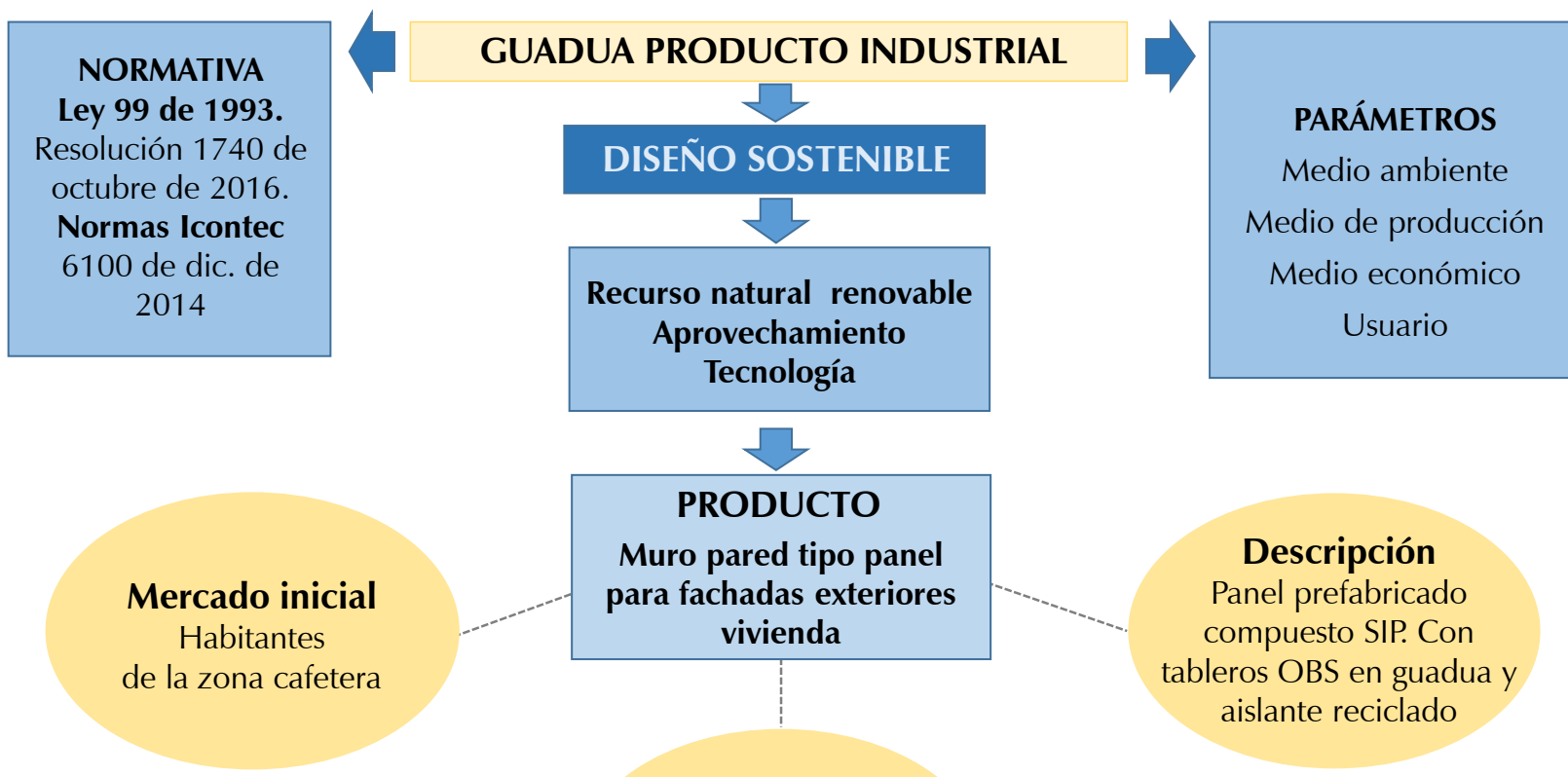

PRODUCTO

Muro pared tipo panel

para fachadas exteriores vivienda

Descripción

Panel prefabricado compuesto SIP. Con tableros OBS en guadua y aislante reciclado
Proyección

Mercado nacional e

internacional
(A) Figura 13. Marco conceptual aplicado a la transformación de la guadua Fuente: elaboración propia, 2017, CC BY

\section{Situación actual de la industria de la guadua en Colombia}

El entorno actual para la industrialización de la guadua tiene como protagonistas al marco legal dado por la la Ley 99 de 1993, "Por la cual se crea el Ministerio del Medio Ambiente, se reordena el Sector Público encargado de la gestión y conservación del medio ambiente y los recursos naturales renovables, se organiza el Sistema Nacional Ambiental, SINA y se dictan otras disposiciones"; la Resolución 1740 de 2016, "Por la cual se establecen lineamientos generales para el manejo, aprovechamiento y establecimiento de guaduales y bambusales, y se dictan otras disposiciones"; las Normas Icontec NTC 6100 (2014), "etiquetas ambientales tipo I. Sello ambiental colombiano. Criterios ambientales para productos primero y segundo grado de transformación de guadua angustifolia Kunth", y la autocertificación forestal del Forest Stewardship Council (FSC) (Consejo de Manejo Forestal); entes y normas que garantizan calidad y futuro al proyecto.

Por otro lado, las organizaciones privadas de los guadueros han permitido la integración en la búsqueda de la tecnificación y mejores condiciones socioeconómicas y ambientales (Figura 13). La fabricación del producto se proyecta, en primera instancia, para consumo de sus propios habitantes de la zona cafetera y en la futura ampliación de su mercado, con la alternativa de utilizar no solo el material residual sino el reciclado.

\section{Discusión}

La investigación fundamenta el proceso de fabricación del panel SIP utilizando materiales no convencionales como la viruta de residuo de la guadua y el cartón reciclado; sus resultados de resistencia a la compresión, aislamiento térmico y acústico demuestran ser un producto viable y competitivo comparado con los que hoy se comercializan, y evidencian que es una alternativa sostenible dentro de los principios de energía pasiva.

Los paneles SIP que se fabrican tienen dos grandes aspectos desfavorables y no sostenibles: la utilización del poliestireno (derivado del petróleo) como aislante interno y el fenol-formaldehído (resina sintética) como adhesivo aplicado en altos porcentajes.

La viruta de guadua como materia prima principal debe alcanzar un secado entre el 4 y $5 \%$ de humedad para garantizar la adherencia entre las virutas a través del prensado; además, para su transformación en hojuelas de dimensiones y diámetros específicos, requiere de una selección previa del material residual o reciclado.

En el Modelo 1 el tablero OSB presenta una buena textura estética y evidencia claramente la disposición cruzada de las virutas u hojuelas (Figura 14), pero menor dureza, con una resistencia horizontal de $1.040 \mathrm{~kg} / \mathrm{m}^{2}$, y $418 \mathrm{~kg} / \mathrm{m}^{2}$ de resistencia vertical, similar a la indicada por los referentes. El adhesivo (poliacetato de vinilo, PVA) requiere mayor fijación sobre las virutas ya que al ser constituidas por fibras muy rígidas y resistentes dejan espacios o cavidades entre ellas. Sin embargo, en el montaje del panel SIP, sus resultados de aislamiento térmico de $+2,90{ }^{\circ} \mathrm{C}$ en temperaturas altas, y de $-1,9{ }^{\circ} \mathrm{C}$ en temperaturas bajas, presentan valores muy similares, y muestran además que los tubos de cartón reciclado utilizados resultan ser una buena alternativa como aislante térmico y acústico. 
갈 Figura 14. Composición de los tableros OSB del referente y las propuestas 1 y 2

Fuente: elaboración propia, 2017, CC BY

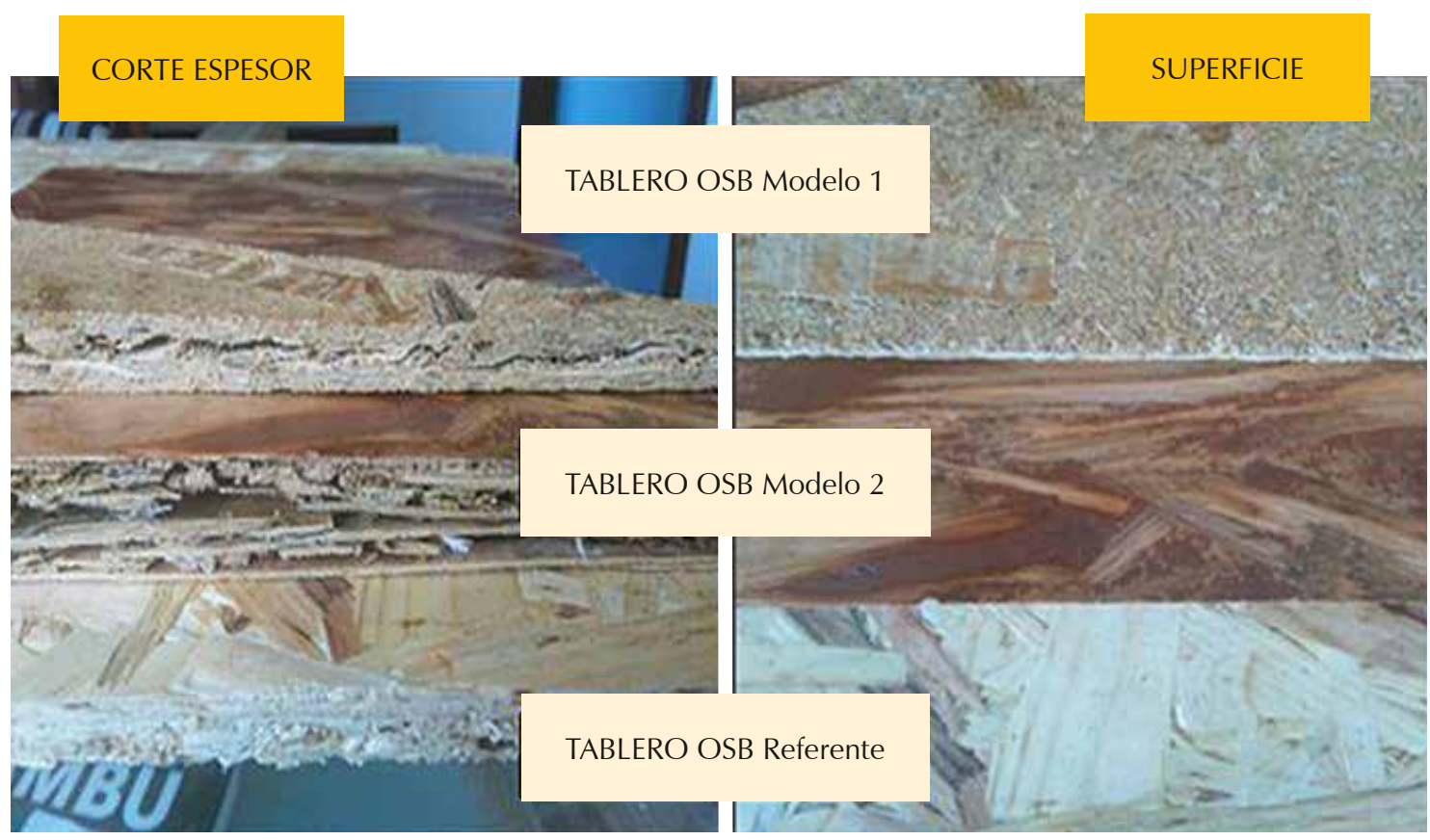

El Modelo 2 presentó una mayor compactación de la viruta de guadua en la elaboración del tablero OSB, para ello fue necesaria la mezcla de estas con otras partículas de guadua muy finas tipo aserrín, que llenaran los espacios libres resultantes entre las hojuelas cruzadas, utilizando el fenol-formaldehído en menores porcentajes, a fin de evitar su toxicidad.

Se presentaron resultados de mayor resistencia horizontal, de $1.970 \mathrm{~kg} / \mathrm{m}^{2}$, y $518 \mathrm{~kg} / \mathrm{m}^{2}$ de resistencia vertical, pero de textura irregular $y$ menor porcentaje de hojuelas en su acabado exterior (Figura 14), los cuales son la característica propia de los tableros OSB. En la conformación del panel SIP, el aislante intermedio de cartón Honeycomb arrojó valores menores en cuanto a la absorción acústica.

Asimismo, los prototipos respecto a su peso por metro cuadrado aproximado de 19 kg están dentro del peso promedio de los referentes, y permiten de esta manera su fácil manipulación en el transporte y montaje.

\section{Conclusiones}

Para una construcción sostenible es necesario implementar estrategias en la selección de materiales, fabricación, montaje y funcionamiento que demuestren una disminución representativa en la emisión de $\mathrm{Co}_{2}$ del producto de construcción, en este caso, durante su ciclo de vida desde la recolección, clasificación del residuo, transformación, fabricación, utilización y de nuevo su reciclaje.

Cabe anotar que en Colombia la normativa está dirigida a la fabricación de tableros aglomerados con partículas de madera, mas no a la elaboración con virutas tipo OSB de los cuales no hay producción en el país y, en consecuencia, no se fabrican paneles SIP de este tipo. De igual forma, los resultados de los factores térmico, acústico y de resistencia son comparados y validados con los de las probetas experimentales, de acuerdo con la información incluida en las fichas técnicas de los referentes.

Partiendo de estas premisas, la investigación se proyecta como una alternativa que sirve de modelo en la utilización de recursos naturales renovables del lugar, transformados, fabricados y utilizados con bajo impacto ambiental. En este caso de estudio, la sociedad del lugar específico está ligada a la economía de la agricultura representada por el cultivo del café, donde la guadua aparece como protagonista del patrimonio sociocultural en la construcción de vivienda, reconocida a su vez como una identidad propia del tejido social y su memoria colectiva.

El muro panel compuesto completa todo su ciclo de vida en el mismo lugar para su propia gente, desde el reciclaje de material residual, transformación, industrialización, comercialización, construcción, uso y retorno al reciclaje, de tal modo que, por obvias razones, sus consumos energéticos disminuyen al no requerir grandes exigencias para su fabricación y transporte durante todo su ciclo de vida.

Finalmente, a través de los datos obtenidos de los modelos experimentales se demostró que para la región aplicada (tropical cálida húmeda), la envolvente térmica se convierte en un sistema de conservación de calor (noche) y enfriamiento (día), manteniendo la temperatura y el aislamiento acústico, y es aporte de energía pasiva de climatización para el confort.

Además, es posible considerar el establecimiento de ajustes en la fabricación y la adaptabilidad, tanto de las estructuras existentes como por construir, lo que tendrá que considerarse como la siguiente etapa en el desarrollo de la investigación. De esta manera, inicialmente se proponen productos de ensamble con materiales de origen natural renovable para la integración arquitectónica en su conjunto, siempre dentro de la filosofía de construcción sostenible a favor de la calidad de vida. 


\section{Referencias}

Apa's Corporate (2015). Tableros de virutas orientales. Guía de productos. Recuperado de https://www.apawood.org/Data/Sites/1/ documents/americalatina/ex-w410-la.pdf

Arquigráfico (2016). Paneles OSB, rapidez y facilidad en la construcción. República Dominicana: arquigrafico arquitectura, ingeniería y construcción. Recuperado de https://arquigrafico.com/paneles-osb-rapidez-y-facilidad-en-la-construccin/

Arquimaster (s. f.). Coeficientes de conductividad térmica de materiales (s/ NORMA IRAM 11601). Argentina. Arquimaster.com. ar. Recuperado de http://www.arquimaster. com.ar/articulos/articulo410.htm

Cárdenas, J. P., Muñoz, E., Riquelme, C. e Hidalgo, F. (2015). Análisis de ciclo de vida simplificado aplicado a viviendas de paneles SIP (structural insulated panels). Revista ingeniería de construcción, 30(1), 33-38. Doi: https://dx.doi.org/10.4067/S071850732015000100003

Colorado, A. (s. f.). La guadua. Una maravilla natural de grandes bondades y promisorio futuro [Mensaje en un blog]. Guadua y Bambú. Recuperado de https://guaduaybambu.es.tl/Maravilla-Natural-de-Grandes-Bondades.htm

Egger Inspiración Eurolight (2016). Zoom Colección tableros alveolares. EE.UU.: Egger Eurolight. Recuperado de https://www.egger.com/ downloads/bildarchiv/157000/1 157736 PP_ZOOM_EUROLIGHT_ES-SWE.pdf

Fernández González, A. (1993). Evolución del mundo tecnológico de los tableros de madera. En I Congreso Forestal Español. Congresos forestales: ponencias y comunicaciones (t. IV pp. 273-282). Madrid. Recuperado de http://secforestales.org/publicaciones/index. php/congresos/article/view/3445/3410

Garay, R. M. y Damiani, F. (2013). Efecto de la densidad del tablero y combinación adhesiva sobre propiedades físico-mecánicas críticas en tableros OSB fabricados con maderas nativas chilenas. Bosque (Valdivia), 34(1), 13-22. Doi: https://dx.doi.org/10.4067/ S0717-92002013000100003

Giraldo, E. (2003). Aspectos generales de la guadua angustifolia Kunth. Propagación y manejo silvicultural sostenible. En III Seminario Internacional del Bambú (pp. 16-29). San Felipe: Fundación para la Investigación Agrícola DANAC. Recuperado de http://
www.mucubaji.com/guaquira/ArchivosAnexos/MBambu.pdf

Grupo Isotex (2015). Soluciones tecnológicas para la construcción: eps-poliestireno expandido: especificaciones técnicas. Venezuela: Grupo Isotex. Recuperado de http://www.grupoisotex.com/eps/

Klasspanel (s.f). ¿Qué son los paneles SIP? Concepción: Klasspanel Structural Insulated Panel. Recuperado de http://www.klasspanel.cl/paneles.htm

Ley 99 de 1993. Por la cual se crea el Ministerio del Medio Ambiente, se reordena el Sector Público encargado de la gestión y conservación del medio ambiente y los recursos naturales renovables, se organiza el Sistema Nacional Ambiental (SINA) y se dictan otras disposiciones. Diario Oficial, 41.146, de 22 de diciembre de 1993. Recuperado de http://www.oas.org/dsd/fida/laws/legislation/colombia/colombia 99-93.pdf

Mejía, I, Gallardo, C., Vallejo, J. J., Ramírez, L. G., Arboleda, E. C., Durango, A, et al. (2009). Plantas del género bambusa: importancia y aplicaciones en la industria farmacéutica, cosmética y alimentaria. Vitae, 16(3), 396-405. Recuperado de http://www. scielo.org.co/scielo.php?script=sci_arttext\&pid=S0121-40042009000300014\&l$\mathrm{ng}=\mathrm{en} \& \operatorname{tlng}=\mathrm{es}$

Mejía, M. y Moreno, R. (2013). Estado del arte de la cadena de la guadua en Colombia 2003-2012. Bogotá: Ministerio del Medio Ambiente. Recuperado de http://sigguadua. gov.co/?q= download/file/fid/155

Ministerio de Ambiente y Desarrollo Sostenible (2015). Decreto 1076 de 2015. Por medio del cual se expide el Decreto Único Reglamentario del Sector Ambiente y Desarrollo Sostenible. 26 de mayo del 2015. Recuperado de http://www.parquesnacionales.gov. co/portal/wp-content/uploads/2013/08/ Decreto-Unico-Reglamentario-Sector-Ambiental-1076-Mayo-2015.pdf

Norma Técnica Colombiana NTC 6100 (2014). Etiquetas ambientales tipo 1. Sello ambiental colombiano. Criterios ambientales para productos de primero y segundo grado de transformación de guadua angustifolia Kunth. Bogotá: Icontec. Recuperado de http:// www.minambiente.gov.co/images/AsuntosambientalesySectorialyUrbana/pdf/ Sello ambiental colombiano/NTC 6100 -SAC_Guadua_Angustifolia.pdf
Organización de las Naciones Unidas para la Alimentación y la Agricultura (FAO) (2016). La producción mundial de madera crece impulsada por la construcción y las energías verdes. Roma: FAO. Recuperado de http:// www.fao.org/news/story/es/item/459939/ icode/

Primadera (2017). Laboratorio de Primadera [fotografía de Primadera SAS]. Gachancipá, Cundinamarca, Colombia: Recuperado de www.primadera.com

Ministerio de Ambiente y Desarrollo sostenible (2016). Resolución 1740 de 2016, Por la cual se establecen lineamientos generales para el manejo, aprovechamiento y establecimiento de guaduales y bambusales, y se dictan otras disposiciones. Recuperado de https://diario-oficial.vlex.com.co/vid/resolucion-numero-1740-2016-652582769

Vagge, C. S. y Czajkowski, J. D. (2012). Impacto de la aplicación de la Ley 13059 de eficiencia energética en relación con la nueva Ordenanza de Usos del Suelo de la ciudad de La Plata y la Norma IRAM 11900 de Etiquetado de Edificios. Ambiente Construido, 12(2), 23-35. Recuperado de http:// www.seer.ufrgs.br/ambienteconstruido/article/view/17109/18759

Varela, I. y Chaviano, D. (2013). El bambu: recurso renovable y sostenible para el diseño y construcción. Monografías. Recuperado de https://www.monografias.com/trabajos101/ bambu-recurso-renovable-y-sostenible-diseno-y-construccion/bambu-recurso-renovable-y-sostenible-diseno-y-construccion. shtml

Weather Atlas (2016). Colombia, previsión meteorológica e información climática: pronóstico del tiempo, Bogotá, 26 de septiembre de 2016. Recuperado de https://www.weather-col.com 


\section{Enfoque y alcance}

La Revista de Arquitectura (Bogotá) (ISSN 1657-0308 Impresa y E-ISSN 2357-626X en línea) es una publicación seriada de acceso abierto, arbitrada mediante revisión por pares (doble ciego) e indexada, en donde se publican resultados de investigación originales e inéditos.

Está dirigida a la comunidad académica y profesional de las áreas afines a la disciplina. Es editada por la Facultad de Diseño y el Centro de Investigaciones (CIFAR) de la Universidad Católica de Colombia en Bogotá (Colombia).

La principal área científica a la que se adscribe la Revista de Arquitectura (Bogotá) según la OCDE es:

Gran área: 6. Humanidades

Área: 6.D. Arte

Disciplina: 6D07. Arquitectura y Urbanismo

También se publican artículos de las disciplinas como 2A02, Ingeniería arquitectónica; 5G03, Estudios urbanos (planificación y desarrollo); 6D07, Diseño.

Los objetivos de la Revista de Arquitectura (Bogotá) son:

- Promover la divulgación y difusión del conocimiento generado a nivel local, nacional e internacional

- Conformar un espacio para la construcción de comunidades académicas y la discusión en torno a las secciones definidas.

- Fomentar la diversidad institucional y geográfica de los autores que participan en la publicación.

- Potenciar la discusión de experiencias e intercambios científicos entre investigadores y profesionales.

- Contribuir a la visión integral de la arquitectura, por medio de la concurrencia y articulación de las secciones mediante la publicación de artículos de calidad.

- Publicar artículos originales e inéditos que han pasado por revisión de pares, para asegurar que se cumplen las normas éticas, de calidad, validez científica, editorial e investigativa.

- Fomentar la divulgación de las investigaciones y actividades desarrolladas en la Universidad Católica de Colombia.
Palabras clave de la Revista de Arquitectura (Bogotá): arquitectura, diseño, educación arquitectónica, proyecto y construcción, urbanismo.

Idiomas de publicación: español, inglés, portugués y francés.

Título abreviado: Rev. Arquit.

Titulo corto: RevArq

\section{Políticas de sección}

La revista se estructura en tres secciones correspondientes a las líneas de investigación activas y aprobadas por la institución, y dos complementarias, que presentan dinámicas propias de la Facultad de Diseño y las publicaciones relacionadas con la disciplina.

Cultura y espacio urbano. En esta sección se publican los artículos que se refieren a fenómenos sociales en relación con el espacio urbano, atendiendo aspectos de la historia, el patrimonio cultural y físico, y la estructura formal de las ciudades y el territorio.

Proyecto arquitectónico y urbano. En esta sección se presentan artículos sobre el concepto de proyecto, entendido como elemento que define y orienta las condiciones proyectuales que devienen en los hechos arquitectónicos o urbanos, y la forma como estos se convierten en un proceso de investigación y nuevo de conocimiento. También se presentan proyectos que sean resultados de investigación, los cuales se validan por medio de la ejecución y transformación en obra construida del proceso investigativo. También se contempla la publicación de investigaciones relacionadas con la pedagogía y didáctica de la arquitectura, el urbanismo y el diseño.

Tecnología, medioambiente y sostenibilidad. En esta sección se presentan artículos acerca de sistemas estructurales, materiales y procesos constructivos, medioambiente y gestión, relacionados con los entornos social-cultural, ecológico y económico.

Desde la Facultad. En esta sección se publican artículos generados en la Facultad de Diseño, relacionados con las actividades de docencia, extensión, formación en investigación o internacionalización, las cuales son reflejo de la dinámica y de las actividades realizadas por docentes, estudiantes y egresados; esta sección no puede superar el $20 \%$ del contenido.

Textos. En esta sección se publican reseñas, traducciones y memorias de eventos relacionados con las publicaciones en Arquitectura y Urbanismo.

\section{A Frecuencia de publicación}

Desde 1999 y hasta el 2015, la Revista de Arquitectura (Bogotá) publicó un volumen al año, a partir del 2016 se publicarán dos números por año en periodo anticipado, enero-junio y julio-diciembre, pero también maneja la publicación anticipada en línea de los artículos aceptados (versión Post-print del autor).

La Revista de Arquitectura (Bogotá) se divulga mediante versiones digitales (PDF, HTML, EPUB, XML) e impresas con un tiraje de 700 ejemplares, los tiempos de

Universidad Católica de Colombia (2018,
julio-diciembre).
Revista de Arquitectura (Bogotá),
20(2), I-I28. Doi: I0.I47/8
ISSN: 1657-0308
E-ISSN: 2357-626X
Especificaciones:
Formato: 34 x $24 \mathrm{~cm}$
Papel: Mate II5 g
Tintas: Negro y policromía

producción de estas versiones dependerán de los cronogramas establecidos por la editorial.

Los tiempos de recepción-revisión-aceptación pueden tardar entre seis y doce meses dependiendo del flujo editorial de cada sección y del proceso de revisión y edición adelantado.

Con el usuario y contraseña asignados, los autores pueden ingresar a la plataforma de gestión editorial y verificar el estado de revisión, edición o publicación del artículo.
A Canje

La Revista de Arquitectura está interesada en establecer canje con publicaciones académicas, profesionales o científicas del área de Arquitectura y Urbanismo, como medio de reconocimiento y discusión de la producción científica en el campo de acción de la publicación.

\section{Mecanismo}

Para establecer canje por favor descargar, diligenciar y enviar el formato: RevArq FP20 Canjes 
Universidad Católica de Colombia

Presidente

Édgar Gómez Betancourt

Vicepresidente - Rector

Francisco José Gómez Ortiz

Vicerrector Jurídico

Edwin de Jesús Horta Vásquez

Vicerrector Administrativo

Édgar Gómez Ortiz

Vicerrector Académico

Elvers Medellín Lozano

Director de Investigaciones

Edwin Daniel Durán Gaviria

Directora Editorial

Stella Valbuena García

\section{Facultad de Diseño}

Decano

Werner Gómez Benítez

Director de docencia

Jorge Gutiérrez Martínez

Directora de extensión

Adriana Pedraza Pacheco

Director de investigación

Hernando Verdugo Reyes

Director de gestión de calidad

Augusto Forero La Rotta

Comité asesor externo

Facultad de Diseño

Édgar Camacho Camacho

Martha Luz Salcedo Barrera

Samuel Ricardo Vélez
Facultad de Diseño

Centro de Investigaciones - CIFAR
Revista de acceso abierto

arbitrada e indexada

Publindex: Categoría B. Índice Bibliografico Nacional IBN.

Esci: Emerging Source Citation Index.

Doaj: Directory of Open Access Journals.

Redalyc: Red de Revistas Cientificas de América Latina y el Caribe, España y Portugal.

SciELO: Scientific Electronic Library Online - Colombia

Redib: Red Iberoamericana de Innovación y Conocimiento Cientifico.

Ebsco: EBSCOhost Research Databases.

Clase: Base de datos bibliográfica de revistas de ciencias sociales y

humanidades.

Latindex: Sistema Regional de Información en Línea para Revistas

Cientificas de América Latina, el Caribe, España y Portugal (Directorio

y catálogo).

Dialnet: Fundación Dialnet - Biblioteca de la Universidad de La Rioja.

LatinRev: Red Latinoamericana de Revistas Académicas en Ciencias

Sociales $y$ Humanidades.

Proquest: ProQuest Research Library.

Miar: Matrix for the Analysis of Journals.

Sapiens Research: Ranking de las mejores revistas colombianas según visibilidad internacional.

Actualidad Iberoamericana: (Índice de Revistas) Centro de Informació Tecnológica (CIT).

Google Scholar

Arla: Asociación de Revistas latinoamericanas de Arquitectura.

Editorial

Av. Caracas $N^{\circ} 46-72$, piso

Teléfono: 3277300 Ext. 5145

editorial@ucatolica.edu.co

www.ucatolica.edu.co

http://publicaciones.ucatolica.edu.co/

Impresión:

JAVEGRAF

Calle 46A No82-54 Int. 2

Bogotá, D. C., Colombia

http://www.javegraf.com.co/index.php

Agosto de 2018

\section{Revista de Arquitectura \\ (Bogotá)}

Director

Werner Gómez Benítez

Editor

César Eligio-Triana

Editores de sección

(1) Myriam Stella Díaz Osorio

(1) Carolina Rodríguez-Ahumada

(1) Anna Maria Cereghino Fedrigo

\section{Equipo editorial}

Coordinadora editorial

María Paula Godoy Casasbuenas mpgodoy@ucatolica.edu.co

Diseño y montaje

Juanita Isaza

juanaisaza@gmail.com

Traductoras

Inglés

Erika Tanacs

etanacs25@gmail.com

Portugués

Roanita Dalpiaz

roanitad@gmail.com

Correctora de estilo

María José Díaz Granados M.

mariajose_dgm@yahoo.com.co

Página Web

Centro de investigaciones (CIFAR)

Distribución y canjes

Claudia Álvarez Duquino

calvarez@ucatolica.edu.co
Comité editorial y científico

Cultura y espacio urbano

Carlos Mario Yory, PhD

Universidad Católica de Colombia. Bogotá, Colombia

Sonia Berjman, $\mathrm{PhD}$

ICOMOS-IFLA, Buenos Aires, Argentina

Juan Carlos Pérgolis, MSc Universidad Piloto de Colombia. Bogotá, Colombia

Beatriz García Moreno, PhD

Universidad Nacional de Colombia. Bogotá, Colombia

Proyecto arquitectónico y urbano

Jean-Philippe Garric, PhD, HDR

Université Paris I Panthéon-Sorbonne. Paris, Francia

Debora Domingo Calabuig, PhD

Universidad Politécnica de Valencia, España

Dania González Couret, PhD

Universidad Tecnológica de La Habana, Cuba

Hugo Mondragón López, PhD Pontificia Universidad Católica de Chile. Santiago, Chile

Juan Pablo Duque Cañas, PhD

Universidad Nacional de Colombia. Bogotá, Colombia

Tecnología, medioambiente y sostenibilidad

Mariano Vázquez Espí, PhD

Universidad Politécnica de Madrid, España

Denise Helena Silva Duarte, PhD Universidade de São Paulo (USP), Brasil

Luis Carlos Herrera Sosa, PhD Universidad Autónoma de Ciudad Juárez, México

Claudio Varini, PhD

Universidad Católica de Colombia. Bogotá, Colombia

Luis Gabriel Gómez Azpeitia, PhD Universidad de Colima. Colima, México 


\section{Contenido}

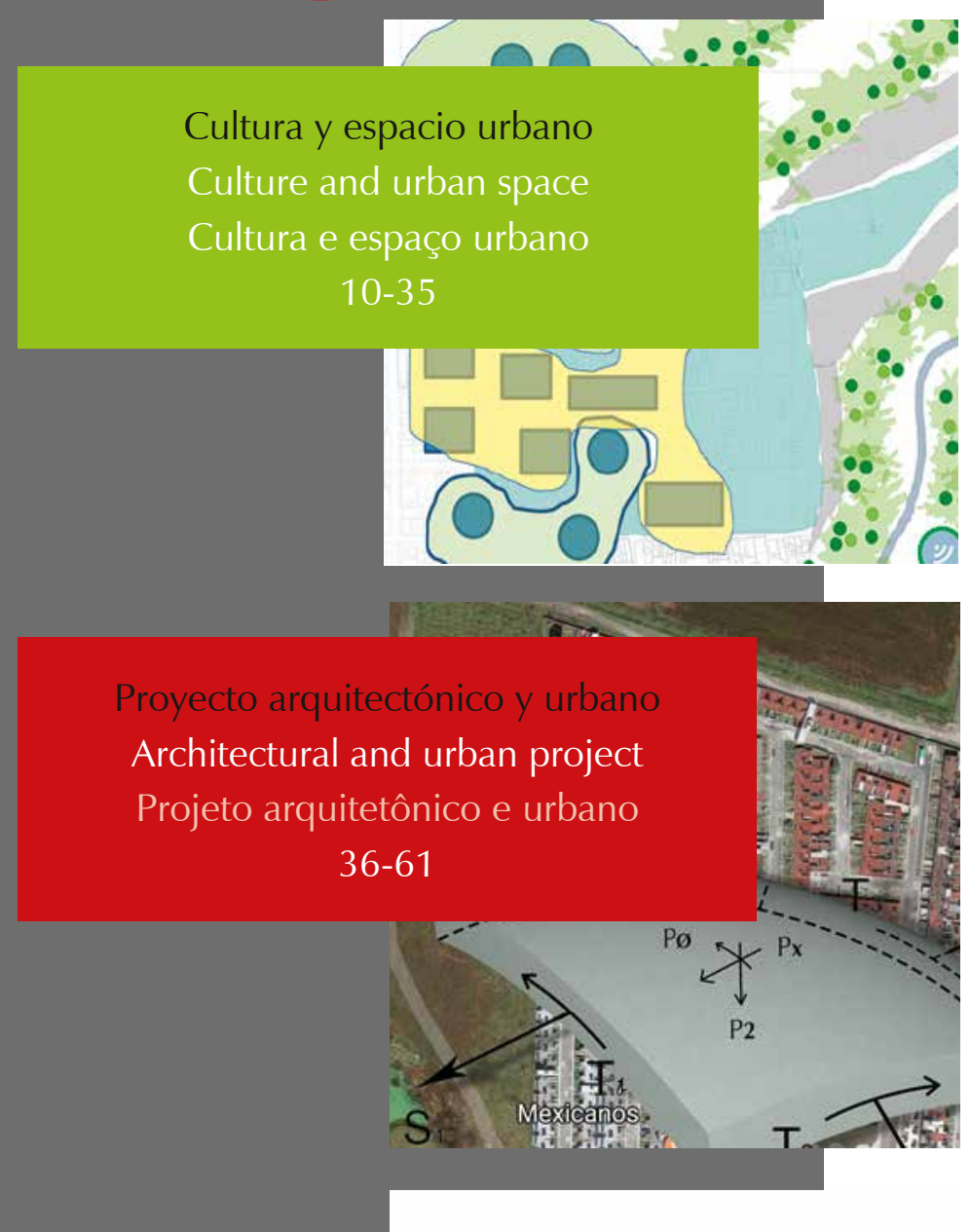

Tecnología, medioambiente

y sostenibilidad

Technology, environment and sustainability

Tecnologia, meio ambiente e sustentabilidade

62-89
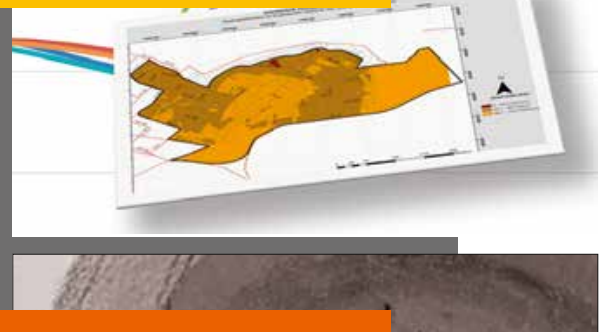

Desde la Facultad

From the Faculty

Da faculdade

90-109
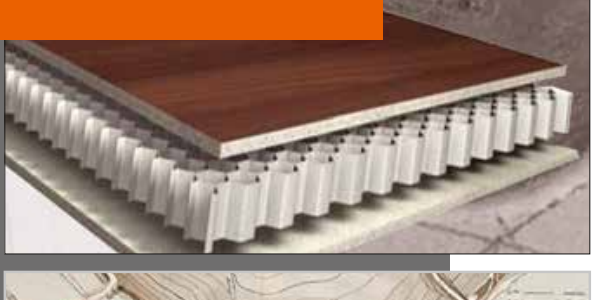

Textos

Texts

Textos

110-126

Los artículos científicos como herramienta de aprendizaje en las escuelas de arquitectura

Carolina Rodríguez-Ahumada

Pág. 3 ES

Paisaje urbano y espacio público como expresión de la vida cotidiana

Morella Briceño-Ávila

Pág. 10

\section{ES EN}

Habitar la quebrada: conformación de gradientes en las trazas vernaculares de los sectores altos de Valparaíso

\section{Omar Eduardo Cañete-Islas}

Juan Luis Moraga-Lacoste

Felipe Mateo López-Flores

Pág. 20

ES

Láminas cilíndricas en la arquitectura colombiana del siglo XX

Jorge Galindo-Díaz

Pág. 36

\section{ES EN}

Retórica simbólica en el espacio arquitectónico

Una mirada antropológica de la casa en la

sobremodernidad

Eska Elena Solano-Meneses

Pág. 51

ES

Ecoenvolventes: análisis del uso de fachadas ventiladas en clima cálido-húmedo

\footnotetext{
Sara Luciani-Mejía

Rodrigo Velasco-Gómez

Roland Hudson
}

Pág. 62

ES

Estrategias metodológicas de análisis urbano frente al cambio climático

Matriz para el diseño adaptativo en asentamientos informales

Adriana Patricia López-Valencia

Oswaldo López-Bernal

Pág. 78

ES

Muro panel térmico estructural compuesto

en guadua y cartón

Modelo experimental aplicado al clima de

la zona cafetera

Renato Cassandro-Cajiao

Pág. 90

\section{ES EN}

Continuidad y transformaciones de modelos

pedagógicos en la École Polytechnique (1867-1910)

Estelle Thibault

Traductores

Andrés Ávila-Gómez

Diana Carolina Ruiz

Pág. 110

ES 
La postulación de un artículo a la Revista de Arquitectura (Bogotá) indica que- el o los autores certifican que conocen y aceptan la política editorial, para lo cual firmarán en original y remitirán el formato RevArq FP00 Carta de originalidad.

La Revista de Arquitectura (Bogotá) maneja una política de Autoarchivo VERDE, según las directrices de SHERPA/RoMEO, por lo cual el autor puede:

- Pre-print del autor: Archivar la versión pre-print (la versión previa a la revisión por pares

- Post-print del autor: Archivar la versión post-print (la versión final posterior a la revisión por pares

- Versión de editor/PDF: Archivar la versión del editor - PDF/HTML/XLM en la maqueta de la Revista de Arquitectura (Bogotá).

El Autoarchivo se debe hacer respetando la licencia de acceso abierto, la integridad y la imagen de la Revista de Arquitectura (Bogotá), también se recomienda incluir la referencia, el vínculo electrónico y el DOI.

El autor o los autores son los titulares del Copyright (c) del texto publicado y la Editorial de la Revista de Arquitectura (Bogotá) solicita la firma de una autorización de reproducción del artículo (RevArq FP03 Autorización reproducción), la cual se acoge a la licencia CC, donde se expresa el derecho de primera publicación de la obra.

La Revista de Arquitectura (Bogotá) se guía por las normas internacionales sobre propiedad intelectual y derechos de autor, y de manera particular el artículo 58 de la Constitución Política de Colombia, la Ley 23 de 1982 y el Acuerdo 172 del 30 de septiembre de 2010 (Reglamento de propiedad intelectual de la Universidad Católica de Colombia)

Para efectos de autoría y coautoría de artículos se diferencian dos tipos: "obra en colaboración" y "obra colectiva". La primera es aquella cuya autoría corresponde a todos los participantes al ser fruto de su trabajo conjunto. En este caso, quien actúa como responsable y persona de contacto debe asegurar que quienes firman como autores han revisado y aprobado la versión final, y dan consentimiento para su divulgación. La obra colectiva es aquella en la que, aunque participan diversos colaboradores, hay un autor que toma la iniciativa la coordinación y realización de dicha obra. En estos casos, la autoría corresponderá a dicha persona (salvo pacto en contrario) y será suficiente únicamente con su autorización de divulgación.

El número de autores por artículo debe estar justificado por el tema, la complejidad y la extensión, y no deberá ser superior a la media de la disciplina, por lo cual se recomienda que no sea mayor de cinco. El orden en que se enuncien corresponderá a los aportes de cada uno a la construcción del texto, se debe evitar la autoría ficticia o regalada. Si se incluyen más personas que trabajaron en la investigación se sugiere que sea en calidad de colaboradores o como parte de los agradecimientos. La Revista de Arquitectura (Bogotá) respetará el número y el orden en que figuren en el original remitido. Si los autores consideran necesario, al final del artículo pueden incluir una breve descripción de los aportes individuales de cada uno de firmantes.

La comunicación se establece con uno de los autores, quien a su vez será el responsable de informar a los demás autores de las notificaciones emitidas por la Revista de Arquitectura (Bogotá).

En virtud de mantener el equilibro de las secciones y las mismas oportunidades para todos los participantes, un mismo autor puede postular dos o más artículos de manera simultánea; si la decisión editorial es favorable y los artículos son aceptados, su publicación se realizará en números diferentes.

\section{A Acceso abierto}

La Revista de Arquitectura (Bogotá), en su misión de divulgar la investigación y apoyar el conocimiento y la discusión en los campos de interés, proporciona acceso abierto, inmediato e irrestricto a su contenido de manera gratuita mediante la distribución de ejemplares impresos y digitales. Los interesados pueden leer, descargar, guardar, copiar y distribuir, imprimir, usar, buscar o referenciar el texto completo o parcial de los artículos o la totalidad de la Revista de Arquitectura (Bogotá).

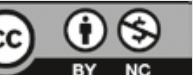

Esta revista se acoge a la licencia Creative Commons (CC BY NC de Atribución - No comercial 4.0 Internacional): "Esta licencia permite a otros entremezclar, ajustar y construir a partir de su obra con fines no comerciales, y aunque en sus nuevas creaciones deban reconocerle su autoría y no puedan ser utilizadas de manera comercial, no tienen que estar bajo una licencia con los mismos términos".

La Revista de Arquitectura es divulgada en centros y grupos de investigación, en bibliotecas y universidades, y en las principales facultades de Arquitectura mediante acceso abierto a la versión digital y suscripción anual al ejemplar impreso o por medio de canje, este último se formaliza mediante el formato RevArq FP20 Canjes

Para aumentar su visibilidad y el impacto de los artículos, se envían a bases de datos y sistemas de indexación y resumen (SIR) y, asimismo, pueden ser consultados y descargados en la página web de la revista.

La Revista de Arquitectura no maneja cobros, tarifas o tasas de publicación de artículo (Article Processing Charge-APC), o por el sometimiento de textos a la publicación.

\section{(1)Ética y buenas prácticas}

La Revista de Arquitectura se compromete a cumplir y respetar las normas éticas en todas las etapas del proceso de publicación. Los autores de los artículos publicados darán cumplimiento a los principios éticos contenidos en las diferentes declaraciones y legislaciones sobre propiedad intelectual y derechos de autor específicos del país donde se realizó la investigación. En consecuencia, los autores de los artículos postulados y aceptados para publicar, que presentan resultados de investigación, deben firmar la declaración de originalidad (formato RevArq FP00 Carta de originalidad).

La Revista de Arquitectura reconoce y adopta los principios de transparencia y buenas prácticas descritos por COPE, "Principles of Transparency and Best Practice in Scholarly Publishing" (2015).

El equipo editorial tiene la obligación de guardar la confidencialidad acerca de los artículos recibidos, y abstenerse de usar en sus propias investigaciones datos, argumentos o interpretaciones hasta tanto el artículo no sea publicado. También debe ser imparcial y gestionar los artículos de manera adecuada y en los plazos establecidos. La selección de revisores se hará con objetividad y estos deberán responder a la temática del artículo.

El editor, los autores y los revisores deben seguir las normas éticas internacionales definidas por el Committee on Publication Ethics (COPE), con el fin de evitar casos de:

- Fabricación, falsificación u omisión de datos.

- Plagio y autoplagio.

- Publicación redundante, duplicada o fragmentada.

- Omisión de referencias a las fuentes consultadas.

- Utilización de contenidos sin permiso o sin justificación.

- Apropiación individual de autoría colectiva.

- Cambios de autoría.

- Conflicto de interés (CDI) no revelado o declarado.

- Otras que pudieran surgir en el proceso de investigación y publicación. La fabricación de resultados se genera al mostrar datos inventados por los autores; la falsificación resulta cuando los datos son manipulados y cambiados a capricho de los autores; la omisión se origina cuando los autores ocultan deliberadamente un hecho o dato. El plagio se da cuando un autor presenta como ideas propias datos creados por otros. Los casos de plagio son los siguientes: copia directa de un texto sin entrecomillar o citar la fuente, modificación de algunas palabras del texto, paráfrasis y falta de agradecimientos; el autoplagio se da cuando el mismo autor reutiliza material propio que ya fue publicado, pero sin indicar la referencia al trabajo anterior. La revista se apoya en herramientas digitales que detectan cualquiera de estos casos en los artículos postulados, y es labor de los editores y revisores velar por la originalidad y fidelidad en la citación. La publicación redundante o duplicada se refiere a la copia total, parcial o alterada de un trabajo ya publicado por el mismo autor

En caso de sospechar de alguna mala conducta se recomienda seguir los diagramas de flujo elaborados por COPE (2008), con el fin de determinar las acciones correspondientes.

La Revista de Arquitectura se reserva el derecho de retractación de publicación de aquellos artículos que, posterior a su publicación, se demuestre que presentan errores de buena fe, o cometieron fraudes o malas prácticas científicas. Esta decisión se apoyará en "Retraction Guidelines" (COPE, 2009). Si el error es menor, este se podrá rectificar mediante una nota editorial de corrección o una fe de erratas. Los autores también tienen la posibilidad de solicitar la retractación de publicación cuando descubran que su trabajo presenta errores graves. En todos los casos se conservará la versión electrónica y se harán las advertencias de forma clara e inequívoca.

\section{A Privacidad y manejo de la información.} Habeas Data

Para dar cumplimiento a lo previsto en el artículo 10 del Decreto 1377 de 2013, reglamentario de la Ley 1581 de 2012, y según el Acuerdo 002 del 4 de septiembre de 2013 de la Universidad Católica de Colombia, "por el cual se aprueba el manual de políticas de tratamiento de datos personales":

La Universidad Católica de Colombia, considerada como responsable o encargada del tratamiento de datos personales, manifiesta que los datos personales de los autores, integrantes de los comités y pares revisores, se encuentran incluidos en nuestras bases de datos; por lo anterior, y en cumplimiento de las disposiciones legales vigentes, la Universidad solicitará siempre su autorización, para que en desarrollo de sus funciones propias como Institución de Educación Superior, en especial las relacionadas con la docencia, la extensión y la investigación, la Universidad Católica de Colombia pueda recolectar, recaudar, almacenar, usar, circular, suprimir, procesar, intercambiar, compilar, dar tratamiento, actualizar, transmitir o transferir a terceros países y disponer de los datos que le han suministrado y que han sido incorporados en las bases de datos de todo tipo que reposan en la Universidad.

La Universidad Católica de Colombia queda autorizada, de manera expresa e inequívoca, en los términos señalados por el Decreto 1377 de 2013, para mantener y manejar la información de nuestros colaboradores (autores, integrantes de los diferentes comités y pares revisores); así mismo, los colaboradores podrán ejercer sus derechos a conocer, actualizar, rectificar y suprimir sus datos personales, para lo cual se han dispuesto las siguientes cuentas de correo electrónico: 
La Revista de Arquitectura (Bogotá) recibe artículos de manera permanente. Los artículos se procesan a medida que se postulan, dependiendo el flujo editorial de cada sección.

El idioma principal es el español, y como opcionales están definidos el inglés, el portugués y el francés; los textos pueden ser escritos y presentados en cualquiera de estos.

Los artículos postulados deben corresponder a las categorías universalmente aceptadas como producto de investigación, ser originales e inéditos y sus contenidos responder a criterios de precisión, claridad y brevedad.

Como punto de referencia se pueden tomar las tipologías y definiciones del Índice Bibliográfico Nacional, Publindex (2010) que se describen la continuación:

1. Artículo de revisión: documento resultado de una investigación terminada donde se analizan, sistematizan e integran los resultados de investigaciones publicadas o no publicadas, sobre un campo en ciencia o tecnología, con el fin de dar cuenta de los avances y las tendencias de desarrollo. Se caracteriza por presentar una cuidadosa revisión bibliográfica de por lo menos 50 referencias.
2. Artículo de investigación científica y tecnológica: documento que presenta, de manera detallada, los resultados originales de proyectos terminados de investigación. La estructura generalmente utilizada contiene cuatro apartes importantes: introducción, metodología, resultados y conclusiones.

3. Artículo de reflexión: documento que presenta resultados de investigación terminada desde una perspectiva analítica, interpretativa o crítica del autor, sobre un tema específico, recurriendo a fuentes originales.

Adicional a estas tipologías, se pueden presentar otro tipo de artículos asociados a procesos de investigación-creación y/o investigación proyectual. En todos los casos se debe presentar la información suficiente para que cualquier investigador pueda reproducir la investigación y confirmar o refutar las interpretaciones defendidas y sea evidente el aporte a la disciplina.

En todos los casos se debe presentar la información suficiente para que cualquier investigador pueda reproducir la investigación y confirmar o refutar las interpretaciones defendidas.

\section{(A) Instrucciones para postular artículos}

Postular el artículo en la página web de la Revista de Arquitectura (Bogotá) y adjuntar comunicación escrita dirigida al editor RevArq_FP00 Carta de originalidad (debidamente firmada por todos los autores en original); de igual manera, se debe diligenciar el formato de hoja de vida RevArq FP01 Hoja de Vida (una por cada autor).

En la comunicación escrita el autor expresa que conoce y acepta la política editorial de la Revista de Arquitectura (Bogotá), que el artículo no está postulado para publicación simultáneamente en otras revistas u órganos editoriales y que no existe conflicto de intereses (ver modelo RevArq FP06 CDI) y que, de ser aceptado, concederá permiso de primera publicación, no exclusiva a nombre de la Universidad Católica de Colombia como editora de la revista.

Los artículos deben tener en cuenta las siguientes recomendaciones:

- En la primera página del documento se debe incluir:

Tírulo: no exceder 15 palabras

Subtítulo: opcional, complementa el título o indica las principales subdivisiones del texto.

Nombre del autor o autores: nombres y apellidos completos o según modelo de citación adoptado por el autor para la normalización de los nombres del investigador. Como nota al pie (máximo 150 palabras): formación académica, experiencia profesional e investigativa, vinculación laboral, código https://orcid.org/, premios o reconocimientos, publicaciones representativas e información de contacto, correo electrónico.

Filiación institucional: debajo del nombre se debe declarar la ins-titución en la cual se desarrolló el producto, de la cual recibió apoyo o aquella que respalda el trabajo investigativo.

Resumen: debe ser analítico, se redacta en un solo párrafo, da cuenta del tema, el objetivo, la metodología, los resultados y las conclusiones; no debe exceder las 150 palabras.

Palabras clave: cinco palabras o grupo de palabras, ordenadas alfabéticamente y que no se encuentren en el título o subtítulo; estas sirven para clasificar temáticamente al artículo. Se recomienda emplear principalmente palabras definidas en el tesauro de la Unesco (http://databases. unesco.org/thessp/), en el tesauro de Arte \& Arquitectura (C) (www.aatespanol.cl), o Vitruvio (http://vocabularyserver.com/vitruvio/)

También se recomienda incluir título, resumen y palabras clave en segundo idioma.

- La segunda página y siguientes deben tener en cuenta:

El cuerpo del artículo se divide en: Introducción, Metodología, Resultados y Discusión de resultados; posteriormente se presentan las Conclusiones, y luego las Referencias bibliográficas y los Anexos (método IMRYD). Las tablas y figuras se deben incorporar en el texto.

Descripción del proyecto de investigación: en la introducción se debe describir el tipo de artículo y brevemente el marco investigativo del cual es resultado y diligenciar el formato (RevArq FP02 Info Proyectos de Investigación).

TEXTO: todas las páginas deben venir numeradas y con el título de artículo en la parte superior de la página. Márgenes de $3 \mathrm{~cm}$ por todos los lados, interlineado doble, fuente Arial o Times New Roman de 12 puntos, texto justificado (Ver plantilla para presentación de artículos). La extensión de los artículos debe ser de alrededor de 5.000 palabras ( \pm 20 páginas, incluyendo gráficos, tablas, referencias, etc.); como mínimo 3.500 y máximo 8.000 palabras. Se debe seguir el estilo vigente y recomendado en el Manual para Publicación de la American Psychological Association (APA). (Para mayor información véase http://www.apastyle.org/)
Citas y notas al pie: las notas aclaratorias o notas al pie no deben exceder cinco líneas o 40 palabras, de lo contrario estas deben ser incorporadas al texto general. Las citas pueden ser:

Corta: (con menos de 40 palabras) se incorporan al texto y pueden ser: textuales (se encierran entre dobles comillas), parafraseo o resumen (se escriben en palabras del autor dentro del texto).

Cita textual extensa: (mayor de 40 palabras) debe ser dispuesta en un renglón y un bloque independiente con sangrías y omitiendo las comillas, no olvidar en ningún caso la referencia del autor (Apellido, año, página).

Referencias: como modelo para la construcción de referencias se emplea el estilo recomendado en el Manual para Publicación de la American Psychological Association (APA) (http://www.apastyle.org/).

Siglas: en caso de emplear siglas en el texto, las figuras o las tablas, se debe proporcionar la equivalencia completa la primera vez que se empleen y encerrarlas entre paréntesis. En el caso de citar personajes reconocidos se deben colocar nombres o apellidos completos, nunca emplear abreviaturas.

Figuras y tablas: las figuras (gráficos, diagramas, ilustraciones, planos, mapas o fotografías) y las tablas deben ir numeradas y contener título o leyenda explicativa relacionada con el tema del artículo, que no exceda las 15 palabras (Figura 1. xxxxx, Tabla 1. xxxx, etc.) y la procedencia (fuente: autor o fuente, año, página). Estas se deben referenciar en el texto de forma directa o entre paréntesis; se recomienda hacerlo con referencias cruzadas.

También se deben entregar en medio digital, independiente del texto, en formatos editables o abiertos. La marcación de los archivos debe corresponder a la incluida en el texto. Según la extensión del artículo se deben incluir de 5 a 10 gráficos. Ver guía para la búsqueda de imágenes de dominio público o bajo licencias Creative Commons (CC).

El autor es el responsable de adquirir los derechos o las autorizaciones de reproducción a que haya lugar para imágenes o gráficos tomados de otras fuentes, así como de entrevistas o material generado po colaboradores diferentes a los autores; de igual manera, se debe garantizar la protección de datos e identidades para los casos que sea necesario.

Fotografía: pueden ser entregadas en original para ser digitalizadas, de lo contrario se deben digitalizar con una resolución igual o superior a 300 dpi para imágenes a color y 600 para escala de grises. Los formatos de las imágenes pueden ser TIFF, PSD o JPG, y deben cumplir con las características expresadas en el punto anterior (figuras).

Planimetría: se debe entregar la planimetría original en medio digital, en lo posible en formato CAD, y sus respectivos archivos de plumas o en PDF; de no ser posible, se deben hacer impresiones en tamaño carta con las referencias de los espacios mediante numeración y lista adjunta. Deben tener escala gráfica, escala numérica, norte, coordenadas y localización. En lo posible, no deben contener textos, achurados o tramas.

Para más detalles, consultar el documento RevArq Parámetros para Autores Descripción en el portal web de la Revista de Arquitectura (Bogotá)

\section{Beneficios}

Como reconocimiento a los autores, se les hará envío postal de dos ejemplares de la edición impresa sin ningún costo y entregada en la dirección consignada en el formato de hoja de vida (RevArq FP01); adicionalmente, se enviará el vínculo para la descarga de la versión digital.

También se enviará una constancia informativa en la que se relaciona a publicación del artículo y, de manera opcional, se pueden detallar las fechas del proceso editorial y el arbitraje realizado. 
La selección de revisores se realiza de acuerdo con los siguientes criterios:

- Afinidad temática.

- Formación académica.

- Experiencia investigativa y profesional.

- Producción editorial en revistas similares o en libros resultado de investigación.

El proceso de arbitraje se basa en los principios de equidad e imparcialidad, y en los criterios de calidad y pertinencia.

El desarrollo de la revisión se realiza según el formato (RevArq FP10 Evaluación de artículos) y las observaciones que el revisor considere necesarias en el cuerpo del artículo. En cualquiera de los conceptos que emita el revisor (Aceptar, Publicable con modificaciones, Reevaluable o No publicable), y como parte de la labor formativa y de comunidad académica, el revisor hará sugerencias para mejorar el documento. El revisor podrá solicitar una nueva relectura del artículo después de los ajustes realizados por el autor.

El revisor también deberá diligenciar el formato RevArq FP01 Hoja de Vida, con el fin de certificar y soportar el proceso de revisión ante los SIR que así lo soliciten.

En el proceso de arbitraje se emplea el método doble ciego, los nombres del revisor no serán conocidos por el autor y viceversa. Con el fin de garantizar el anonimato del autor, al artículo postulado se le han podido suprimir nombres, instituciones o imágenes que puedan ser asociadas de manera directa al autor.

Aunque se procura el anonimato, una vez recibida la invitación como par revisor del artículo, el revisor debe cerciorarse de que no exista conflicto de intereses (CDI) o alguna limitante que afecte la revisión o que pueda ser vista como tal (lazos familiares, amistad o enemistad, vínculos contractuales o laborales, posiciones éticas, etc.), de presentarse esta situación se notificara al editor. (Ver modelo RevArq FP06 CDI).

Dada la confidencialidad del proceso de revisión, y considerando los derechos de autor y de propiedad intelectual que pueda haber sobre el material que se entrega, el revisor se compromete a mantener en absoluta reserva su labor, a limitar el uso de la obra entregada solo para el propósito designado y a devolver la documentación remitida una vez concluya la actividad.

El tiempo establecido para las revisiones de pares es de máximo un mes a partir de la confirmación de la recepción de la documentación. Ese plazo podrá ser modificado de mutuo acuerdo entre el editor y el revisor, siempre y cuando no afecte la periodicidad de la revista, la impresión o el tiempo para emitir una respuesta al autor.

Los revisores se acogerán a "COPE Ethical Guidelines for Peer Reviewers" de COPE.

\section{Beneficios}

Como retribución a los revisores se les hará envío postal de un ejemplar de la edición impresa sin ningún costo y entregada en la dirección consignada en el formato de hoja de vida. También, si es de interés para el revisor, podrá hacer la solicitud de alguna de las publicaciones editadas y presentes en el catálogo de publicaciones de la UNIVERSIDAD CATÓLICA DE COLOMBIA, previa aprobación de la Editorial y sujeto a la disponibilidad.

Si lo desea tendrá derecho a una constancia de la colaboración en la revisión de artículos, la cual solo contendrá el periodo en el cua se realizó la actividad. También tendrá la posibilidad de aceptar o no la publicación de su nombre, nacionalidad y nivel máximo de formación en la página web de la Revista de Arquitectura (Bogotá) en su calidad de colaborador.

\section{A Proceso de revisión por pares}

Luego de la postulación del artículo, el editor de la Revista de Arquitectura (Bogotá) selecciona y clasifica los artículos que cumplen con los requisitos establecidos en las directrices para los autores. El editor podrá rechazar en primera instancia artículos, sin recurrir a un proceso de revisión, si los considera de baja calidad o por presentar evidencias de faltas éticas o documentación incompleta.

Los artículos se someterán a un primer dictamen del editor, de los editores de sección y del Comité Editorial, teniendo en cuenta:

- Afinidad temática, relevancia del tema y correspondencia con las secciones definidas.

- Respaldo investigativo.

- Coherencia en el desarrollo del artículo, así como una correcta redacción y ortografía.
- Relación entre las figuras y tablas con el texto del artículo.

En esta revisión se verificará el nivel de originalidad mediante el uso de software especializado (Ithenticate o similar) y recursos digitales existentes para tal fin, también se observará la coherencia y claridad en los apartados del documento (modelo IMRYD) la calidad de las fuentes y la adecuada citación, esto quedará consignado en el formato (RevArq FP09 Revisión de artículos); esta información será cargada a la plataforma de gestión editorial y estará a disposición del autor.

En caso de que el artículo requiera ajustes preliminares, será devuelto al autor antes de ser remitido a revisores. En este caso, el autor tendrá veinte días para remitir nuevamente el texto con los ajustes solicitados.

Después de la preselección se asignan mínimo dos revisores especializados, quienes emitirán su concepto utilizando el formato (RevArq FP10 Evaluación de artículos) y las anotaciones que consideren oportunas en el texto; en esta etapa se garantizará la confidencialidad y el anonimato de autores y revisores (modalidad doble ciego)

Del proceso de revisión se emite uno de los siguientes conceptos que será reportado al autor:

- Aceptar el envío: con o sin observaciones.

- Publicable con modificaciones: se podrá sugerir la forma más adecuada para una nueva presentación, el autor puede o no aceptar las observaciones según sus argumentos. Si las acepta, cuenta con quince días para realizar los ajustes pertinentes.

- Reevaluable: cumple con algunos criterios y debe ser corregido. Es necesario hacer modificaciones puntuales y estructurales al artículo. En este caso, el revisor puede aceptar o rechazar hacer una nueva lectura del artículo luego de ajustado.

- No publicable: el autor puede volver a postular el artículo e iniciar nuevamente el proceso de arbitraje, siempre y cuando se evidencien los ajustes correspondientes.

En el caso de presentarse diferencias sustanciales y contradictorias en los conceptos sobre la recomendación del revisor, el editor remitirá el artículo a un revisor más o a un miembro del Comité Editorial quien podrá actuar como tercer árbitro, con el fin de tomar una decisión editorial sobre la publicación de artículo.

Los autores deberán considerar las observaciones de los revisores o de los editores, y cada corrección incorporada u omitida debe quedar justificada en el texto o en una comunicación adjunta. En el caso que los autores omitan las indicaciones realizadas sin una argumentación adecuada, el artículo será devuelto y no se dará por recibido hasta que no exista claridad al respecto. El editor respetará la independencia intelectual de los autores y a estos se les brindará el derecho de réplica en caso de que los artículos hayan sido evaluados negativamente y rechazados. Los autores, con su usuario y contraseña, podrán ingresar a la plataforma de Gestión Editorial, donde encontrarán los conceptos emitidos y la decisición sobre el artículo.

El editor y el Comité Editorial se reservan el derecho de aceptar o no la publicación del material recibido. También se reservan el derecho de sugerir modificaciones de forma, ajustar las palabras clave o el resumen y de realizar la corrección de estilo. El autor conocerá la versión final del texto antes de la publicación oficial del mismo.

Cuando un artículo es aceptado para su publicación, el autor debe firmar la autorización de reproducción (RevArq FP03 Autorización reproducción). Para más información ver: Política de derechos de autor

\section{Notas aclaratorias:}

La Revista de Arquitectura (Bogotá) busca el equilibrio entre las secciones, motivo por el cual, aunque un artículo sea aceptado o continúe en proceso de revisión, podrá quedar aplazado para ser publicado en un próximo número; en este caso, el autor estará en la posibilidad de retirar la postulación del artículo o de incluirlo en el banco de artículos del próximo número.

El editor y los editores de sección de la Revista de Arquitectura (Bogotá) son los encargados de establecer contacto entre los autores y revisores, ya que estos procesos se realizan de manera anónima.
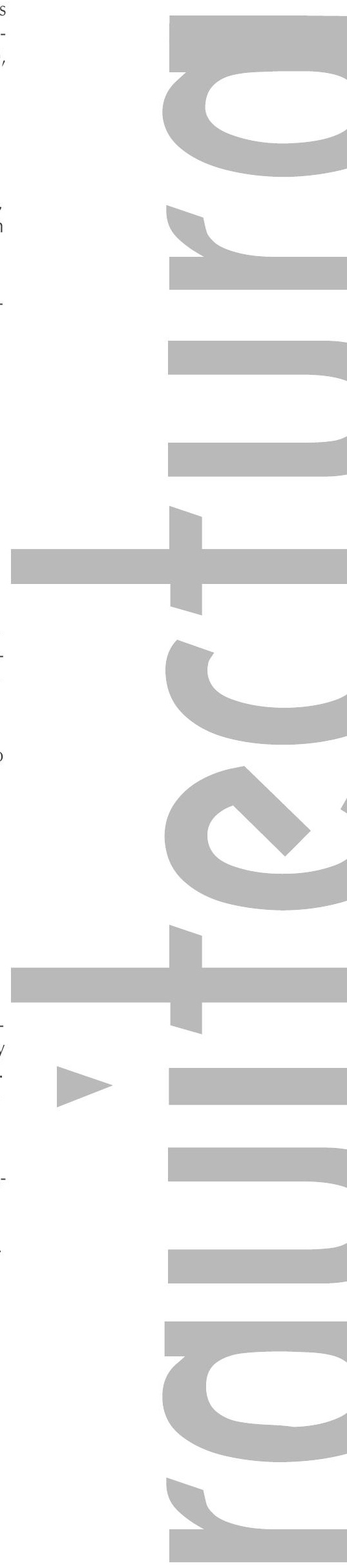

\section{.}

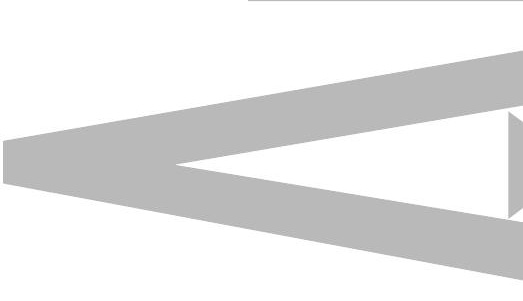


Los artículos científicos como herramienta de aprendizaje en las escuelas de arquitectura

نं Scientific articles as a learning tool in architecture schools

$\ll \quad$ Os artigos científicos como ferramenta de aprendizagem

nas escolas de arquitetura

Carolina Rodriguez-Ahumada

Paisaje urbano y espacio público como expresión 으 de la vida cotidiana

Urban landscape and public space as an expression of everyday life

نั Paisagem urbana e espaço público como expressão da vida cotidiana

Habitar la quebrada: conformación de gradientes en las trazas 을 vernaculares de los sectores altos de Valparaíso

Inhabiting the ravine: Gradient configuration in the vernacular layouts of the

¿ higher sectors of Valparaíso

Habitar a quebrada: conformação de níveis nos traçados vernaculares dos setores altos de Valparaíso

\section{Omar Eduardo Canete-Islas}

Juan Luis Moraga-Lacoste

Felipe Mateo López-Flores

Láminas cilíndricas en la arquitectura colombiana del siglo $X X$ Cylindrical shells in Colombian architecture in the 20th century

Estruturas laminares cilíndricas na arquitetura colombiana do século $X X$ 这 Jorge Galindo-Díaz

Retórica simbólica en el espacio arquitectónico. Una mirada antropológica de la casa en la sobremodernidad

in Symbolic Rhetoric in the Architectural Space: An Anthropological View of the

ن House in the Age of Supermodernity

Retórica simbólica no espaço arquitetônico. Um olhar antropológico da casa na sobremodernidade

\section{Eska Elena Solano-Meneses}

Ecoenvolventes: análisis del uso de fachadas ventiladas en clima ㅈ cálido-húmedo

نं Eco-friendly coverings: Analysis of the use of ventilated facades in hot, humid

ن⿺ weather

Ecoenvolventes: análise do uso de fachadas ventiladas em clima quente úmido

Sara Luciani-Meía

Rodrigo Velasco-Gómez

Roland Hudson

Estrategias metodológicas de análisis urbano frente al cambio œ climático. Matriz para el diseño adaptativo en asentamientos $\stackrel{\infty}{\text { informales }}$

Methodological strategies for urban analysis in the face of climate change. An adaptive design matrix for informal settlements

Estratégias metodológicas de análise urbana ante mudanças climáticas. Matriz para o desenho adaptativo em assentamentos informais

Adriana Patricia López-Valencia

Muro panel térmico estructural compuesto en guadua y - cartónModelo experimental aplicado al clima de la zona cafetera

․ Structural thermal panel wall composed of bamboo and cardboard.

Experimental model applied to the climate of the Coffee Region

$\ltimes$ Muro painel térmico estrutural composto de bambu e papelão. Modelo experimental aplicado ao clima da zona cafeeira

\section{Renato Cassandro-Cajiao}

Continuidad y transformaciones de modelos pedagógicos en la École Polytechnique (1867-1910)

으 Continuity and transformations of teaching models at the École Polytechnique

二 (1867-1910)

ن Continuidade e transformações de modelos pedagógicos na École

¿ Polytechnique (I867-1910) 